\title{
El coronavirus en el ecosistema de los dispositivos móviles: creadores, discursos y recepción
}

\section{Coronavirus in the mobile device ecosystem: developers, discourses and reception}

\author{
Alicia Gil-Torres. Universidad de Valladolid. España. \\ alicia.gil@uva.es \\ $[\mathrm{CV}] \bigcirc \mathrm{G}=0$ \\ Juan Martín-Quevedo. Universidad Rey Juan Carlos. España. \\ juan.martin.quevedo@urjc.es \\ [CV] (1)
}

Salvador Gómez-García. Universidad de Valladolid. España.

salvadorgomez@hmca.uva.es

$[\mathrm{CV}]$ (1) $\mathrm{G}$ - $\mathrm{O}$

Cristina San José-De la Rosa. Universidad de Valladolid. España.

cristina.sanjose@uva.es

$[\mathrm{CV}] \bigcirc \mathrm{R}^{\mathrm{C}} \mathrm{O}$

Este manuscrito es resultado del Proyecto de Investigación $I+D+i$ «Politainment en el entorno de la posverdad: nuevas narrativas, clickbait y gamificación» (CSO2017-84472-R), subvencionado por el Ministerio de Economía, Industria y Competitividad del Gobierno de España para el periodo 2018-2020.

Fechas:

- Inicio de la investigación: 15 de enero de 2020.

- Término de la investigación: 15 de junio de 2020.

Cómo citar este artículo / Referencia normalizada

Gil-Torres, A., Martín-Quevedo, J., Gómez-García, S. y San José-De la Rosa, C. (2020). El coronavirus en el ecosistema de los dispositivos móviles: creadores, discursos y recepción. Revista Latina de Comunicación Social, 78, 329-358. https://www.doi.org/10.4185/RLCS-2020-1480

\section{RESUMEN}

Introducción: Esta investigación explora el impacto de la crisis de la COVID-19 en el ecosistema de las aplicaciones móviles. Metodología: Se parte de la búsqueda y localización de apps sobre COVID19 en las plataformas Google Play y Apple Store para seleccionar aquellas de mayor impacto y difusión a las que se practicó un análisis cuantitativo. Resultados: La investigación se ha centrado en cuatro aspectos: (1) la aparición de estas aplicaciones y su evolución a tenor de la actualidad durante los primeros meses del año 2020; (2) las características, propósitos y rasgos del discurso; (3) qué rasgos identificaron a los emisores y, por último, (4) la recepción que hicieron los usuarios sobre las apps. Discusión: los dos grandes tipos de desarrolladores (entidades gubernamentales e iniciativas privadas) se centraron en aplicaciones de control y diagnóstico de la enfermedad junto a otras que trataban de paliar la creciente demanda de información. 
RLCS, Revista Latina de Comunicación Social, 78, 329-358

[Investigación] DOI: 10.4185/RLCS-2020-1480| ISSN 1138-5820| Año 2020

PALABRAS CLAVE: COVID-19; 2019-nCoV; apps; ecosistema móvil; Android; iOS;

Smartphones.

\begin{abstract}
Introduction: This research explores the impact of the COVID-19 crisis on the ecosystem of mobile applications. Methodology: The search and location of apps on COVID19 on the Google Play and Apple Store platforms is used to select the ones with the greatest impact and diffusion for which a quantitative analysis was performed. Results: The research has focused on four aspects: (1) the appearance of these applications and their evolution according to current events during the first months of 2020; (2) the characteristics, purposes, and features of the discourse; (3) what traits identified the issuers and, finally, (4) the reception that users made about the apps. Discussion: the two main types of developers (government entities and private initiatives) focused on disease control and diagnosis applications, along with others that tried to alleviate the growing demand for information.
\end{abstract}

KEYWORDS: COVID-19; 2019-nCoV; apps; mobile environment; Android; iOS; Smartphones.

\title{
CONTENIDOS
}

1. Introducción. 2. Objetivos. 3. Metodología. 4. Resultados. 4.1. Evolución del ecosistema de las aplicaciones móviles sobre el coronavirus. 4.2. Características de las apps más populares. 4.3. Radiografía de los desarrolladores de las apps sobre la COVID-19. 4.4. La recepción de las apps entre los usuarios. 5. Discusión. 6. Referencias

\section{Introducción}

El 31 de diciembre de 2019, la Organización Mundial de la Salud (WHO) notificó el primer caso de una nueva infección respiratoria que se conocería como COVID-19 o 2019-nCoV (WHO, 2020) y que acabaría extendiéndose por todo el mundo. En las primeras semanas, el epicentro de la enfermedad se situó en la ciudad de Wuhan (China) y los gobiernos local y nacional emprendieron una serie de medidas destinadas a controlar y contener la expansión del virus. El confinamiento general fue complementado con una estrategia de seguimiento de los casos sospechosos, para poder abordar los contagios antes de que se descontrolaran, algo fundamental dado que el período de incubación del virus supone que una persona puede estar infectada y ser contagiosa durante varios días antes de manifestar una sintomatología apreciable.

Con la expansión de los casos registrados, que pronto pasaron de cientos a decenas de miles, el uso de la tecnología de la información, y, particularmente, los smartphones y las aplicaciones (apps) se convirtió en fundamental tanto para la geolocalización ciudadana como para proporcionar información (Ye; Zhou; Wu, 2020). El gobierno chino lanzó varias aplicaciones de monitorización de la población, una estrategia que se mostró especialmente eficaz para evitar la extensión incontrolada de casos por todo el país durante los desplazamientos por el año nuevo chino (31 de enero de 2020) (Chen et al., 2020). Así, el gobierno chino lanzó la app Query of Same Itinerary with Patient, que permitía reconstruir los desplazamientos del usuario durante el último mes para saber si había coincidido con personas infectadas y, si era el caso, recibir asesoramiento inmediato. Igualmente, la app Diagnosed Cases in Community permitía rastrear en qué zonas de cada ciudad se concentraban los casos registrados, para poder planificar mejor las salidas (Pan, 2020).

No fue el único caso. La propagación del virus a escala mundial llevó a otros Estados como Israel, Taiwan o Corea del Sur, a la aprobación de una legislación que permitiera el seguimiento de los datos de geolocalización de los teléfonos móviles. Por otra parte, otra estrategia menos 
agresiva/invasiva, en tanto que requiere la aprobación explícita del ciudadano, fue la elegida por el gobierno de Singapur, que lanzó la aplicación TraceTogether. Ésta permitía rastrear vía Bluetooth los usuarios que habían estado cerca unos de otros de forma que, si se producía un contagio, el Ministerio de Sanidad se ponía en contacto con todos los posibles afectados para hacer un seguimiento (Cho; Ippolito; Yu, 2020). El gobierno español también ha ensayado con aplicaciones similares, aunque de mucho menos alcance, como Asistencia COVID-19, en este caso más orientada al autodiagnóstico y ensayada sólo en cinco comunidades autónomas (La Moncloa, 2020), o Radar COVID, cuya activación se ha producido a lo largo del segundo semestre de 2020 en España.

Si bien es cierto que es pronto para medir el impacto real de estas aplicaciones para reducir el número de contagios, existen indicios de que han tenido un impacto muy positivo, incluso en países en los que sólo un porcentaje relativamente bajo de la población ha instalado estas apps (Howell, 2020), aunque siempre como complemento de otras medidas (Kitchin, 2020). En cualquier caso, el uso de las aplicaciones para el posible diagnóstico y contención de pandemias sólo se ha abordado como un aspecto tangencial. A raíz del brote de ébola de 2014-15 en África Occidental se publicó una revisión sistemática sobre una muestra de 58 apps creadas para la gestión de la crisis (Tom-Aba et al., 2018), pero no tuvo seguimiento con ulteriores artículos. Respecto a las aplicaciones móviles sobre el coronavirus, las investigaciones académicas se han centrado en aspecto prácticos sobre su diseño (Kishore et al., 2020; Betarte et al., 2020). Y aunque ha habido algunos textos publicados en revistas tecnológicas especializadas (Kim, 2020; Gvili, 2020), en general no se les ha prestado atención más allá de las invasiones de la privacidad que generará el uso de estas apps de rastreo (HRW, 2020; Cho, Ippolito; Yu, 2020).

A esto cabe añadir la proliferación de aplicaciones no gubernamentales, y con propósitos diferentes al rastreo, motivadas, por ejemplo, por el deseo de información de la ciudadanía. Un deseo de información alimentado $\mathrm{y}$, en parte, motivado, por la extensa cobertura mediática de todos los asuntos relacionados con la COVID, con hasta un 63,74\% de la información en medios digitales dedicada al coronavirus en España (Lázaro-Rodríguez; Herrera-Viedma, 2020: 7). Este interés también se ha visto reflejado en el aumento del consumo de radio y concretamente de los programas de información durante el confinamiento (Rodero, 2020). El deseo de conseguir información fiable ha estado especialmente presente en las primeras semanas tras la declaración del estado de alarma, marcadas por una gran incertidumbre y un comportamiento de medios e instituciones que oscilaba entre la sobreinformación y el sensacionalismo (Masip et al., 2020; Costa-Sánchez; López García, 2020). En este sentido, los españoles buscaban información mayoritariamente en los medios de comunicación, pero también, aunque en menor medida, a través de medios digitales y búsquedas en Internet (Badía, 2013; Igartua; Ortega-Mohedano; Arcila-Calderón, 2020), vinculadas en muchos casos al uso del smartphone.

Esa situación se ha producido en un contexto en el que la penetración de los smartphones (y de las apps) en la vida cotidiana ha crecido de forma consistente en los últimos años (Berlanga-Fernández et al., 2018; Montero-Díaz, J. et. al.). En 2018 ya se superó el número de líneas de telefonía móvil a la población mundial. Según el informe anual Mobile Economy de la GSMA, al finalizar 2017 se alcanzó un grado de penetración del 66\% (5.000 millones) pero el número de tarjetas SIM empleadas se situó en los 7.800 millones. Esta cifra corresponde al $103 \%$ de la población mundial actual (Muñoz, 2018). Desde la llegada del primer smartphone a principios del siglo XXI, el número total de usuarios de teléfonos inteligentes en todo el mundo no ha parado de crecer, hasta situarse en los 3.200 millones de usuarios de este tipo de dispositivos en el mundo con China (que representa un $27 \%$ del total) a la cabeza (Newzoo, 2019). 
El incremento de dispositivos ha influido para que, en 2019, Internet alcanzara un consumo promedio de 170 minutos diarios por persona, superando a la televisión (167 minutos de media) por primera vez en la historia. Esto se debe a que dentro de ese consumo se engloba el creciente uso de internet en los teléfonos móviles acaparando 130 minutos por día (Statista, 2019). Estos datos se han incrementado ante el confinamiento que se ha sufrido debido al coronavirus. A medida que los países iban limitando la movilidad social, aumentaba el tiempo de uso de los smartphones: en marzo el consumo aumentó en China un 30\% y en Italia, también en el epicentro de la pandemia, un 11\%, con un incremento del 20\% de media mundial en el primer trimestre (App Annie Intelligence, 2020).

No sólo ha aumentado el tiempo dedicado a los móviles, sino que la nueva situación de confinamiento ha propiciado la experimentación y la búsqueda de nuevos usos para los dispositivos, en parte marcados por el deseo de mantener el contacto social (Fu y Lee, 2020), y en parte impulsados por la necesidad de adaptarse al teletrabajo (Anghel, Cozzolino y Lacuesta, 2020). En el primer trimestre de 2020, Google Play acrecentó sus descargas un 5\% anual e iOS un 15\% (App Annie Intelligence, 2020). El aumento ha sido particularmente marcado en las aplicaciones de videoconferencia: sólo en la tercera semana de marzo (14 al 21) se descargaron 62 millones de aplicaciones de este tipo en todo el mundo, un aumento del $45 \%$ respecto a la semana anterior y un 90\% más que ese mismo periodo en 2019 (App Annie Intelligence, 2020). Esto se une a la reacción de la ciudadanía en muchos países, marcada por la búsqueda de fuentes de información alternativas, en muchos casos debido a la desconfianza en instituciones y medios tradicionales (Scolari et al., 2009; Boberg et al., 2020).

Por todo ello, esta investigación se propone explorar cómo se ha transformado el ecosistema de las aplicaciones móviles acerca del coronavirus, un entorno caracterizado por su capacidad para abordar temáticas de actualidad en tiempos muy cortos, debido a la facilidad de desarrollo y a la expansión de las apps (Gómez; Cabeza, 2016; Gómez-García et al., 2019; Navarro-Sierra y Quevedo-Redondo, 2020). Además, se explora la recepción que las audiencias han hecho de estas aplicaciones, tanto en lo respectivo a qué han descargado y a sus reacciones, como, sobre todo, la finalidad de las aplicaciones que han escogido.

\section{Objetivos}

Las cuestiones anteriores subrayan el foco de esta investigación: el rol de las apps de dispositivos móviles en el flujo de informaciones sobre el coronavirus durante los meses iniciales de la pandemia. Debido a la excepcional situación que se estudia, se plantea una investigación exploratoria de corte cuantitativo que identifique el tipo de transformaciones que se han producido en el ecosistema de las plataformas de distribución para aplicaciones móviles en sistemas operativos Android e iOS, así como sus rasgos de producción, consumo y respuestas de los usuarios. Este análisis del ecosistema móvil de apps se plantea en torno a cuatro ejes principales: (1) el surgimiento de este tipo de apps, (2) sus rasgos característicos, (3) la identificación de los emisores y (4) la recepción de las apps por parte de los usuarios. A partir de estos pilares y la fundamentación teórica propuesta en el apartado anterior se proponen las siguientes preguntas de investigación que tratarán de responderse a partir de una serie de variables que también se indican:

$\mathrm{PI}_{1}$. ¿Cuál fue el impacto de la actualidad informativa sobre el COVID-19 en el número de aplicaciones móviles que abordaron esta situación y qué alcance obtuvieron en los diferentes países afectados por el virus? Esta cuestión se abordó a partir de la cantidad y distribución de las apps según sus países de origen y las descargas conseguidas. 
$\mathrm{PI}_{2}$ ¿ ¿A qué tipo de propósito respondieron las apps en relación al COVID-19 y cuáles recibieron una mayor aceptación? Un aspecto que se abordará a partir de las diferentes categorías que reconocen las plataformas de distribución, así como de la codificación de los servicios que ofrecían, con especial atención a las apps que recibieron más descargas.

$\mathrm{PI}_{3}$. ¿Cuál fue el perfil de los desarrolladores de las apps sobre el COVID-19? Para responder a esta pregunta se consideró que la identificación de los emisores es la clave. Así se puede conocer si son los propios gobiernos, empresas o ciudadanos. El número de apps desarrolladas previamente por cada uno de estos perfiles también permite identificar si son profesionales del ecosistema móvil buscando un beneficio o no.

$\mathrm{PI}_{4}$. ¿Qué tipo de recepción y valoración han recibido las apps más descargadas? ¿Cuáles han sido los comentarios que los usuarios han dado de las mismas y en qué aspectos las consideraban eficaces o inútiles? Con esta pregunta se busca conocer cuál es la reacción de los usuarios de estas apps a partir de los comentarios que se han registrado a través de las plataformas de distribución de contenido.

Las cuatro cuestiones anteriores definen el triple frente de esta investigación. El primero de ellos es el análisis de cómo ha sido la evolución cuantitativa de la muestra de apps y sus elementos característicos. En segundo lugar, se busca identificar los rasgos de los desarrolladores y sus apps. Y, por último, observar los elementos que definen cómo los usuarios han acogido este tipo de aplicaciones.

\section{Metodología}

La metodología de esta investigación ha tratado de dar respuesta a este triángulo de intereses a partir de la búsqueda e identificación de todas las apps que tienen como temática algún aspecto relacionado con el coronavirus en el marco del actual desafío académico que supone el desarrollo de un utillaje teórico y metodológico para esta investigación (Costa-Sánchez, 2014; Light; Burgess; Duguay, 2016; Gómez-García et al., 2019; Cano-Orón, Vengut-Climent, \& Moreno-Castro, 2020). Para ello, se realizó una búsqueda a través de palabras clave (COVID-19, coronavirus y 2019-nCoV) y de diferentes operadores booleanos en las plataformas de distribución de contenido Google Play y App Store. Esta búsqueda se realizó con Sensor Tower, un software de monitorización de apps. El cribado inicial se completó con un muestro de bola de nieve (Baltar; Brunet, 2012) gracias a las sugerencias que ofrecían las plataformas a partir de los resultados iniciales. De esta manera, se espera haber localizado la práctica totalidad de las apps más relevantes publicadas de enero de 2020 hasta mayo de este mismo año.

Los resultados arrojaron un total de 415 aplicaciones: 271 correspondían al sistema operativo Android y 144 a iOS. De ellas, 82 estaban disponibles para ambos sistemas y se consideraron duplicadas. Sin embargo, para la codificación de datos se optó por excluir a las aplicaciones de la App Store debido a la opacidad de la plataforma de Apple en ciertas variables fundamentales para esta investigación como, por ejemplo, el país de creación o el número de descargas, factores que ya han evidenciado limitaciones en otras investigaciones (Gómez; Cabeza, 2016).

Por motivos operativos y de integridad analítica, el análisis de contenido se concretó en aquellas apps que a 31 de mayo de 2020 habían superado las 1000 descargas. Es decir, 137 del total de 271 apps que se habían localizado en Android. En otras investigaciones similares (Gómez García et al., 2019; Zamora-Medina; Losada-Díaz; Vázquez-Sande, 2020) se han definido otros umbrales de codificación, pero con poblaciones más numerosas o con una acumulación mayor de descargas por el 
paso del tiempo. A partir de estas consideraciones y debido a la novedad del objeto de estudio, el tamaño de la muestra y la rapidez de los hechos, se decidió fijar el límite en aquellas apps que superaron las 1.000 descargas porque la Organización Mundial de la Salud declaró a la COVID-19 como pandemia el 11 de marzo de 2020 (OMS, 2020) y la recolección de datos fínalizó solo 11 semanas y media después, siendo un plazo corto como para que el fenómeno no siga considerándose como novedoso. Además, en la tabla 1 se observa que el total estimado de descargas es de 128.845.546, de las cuales 128.813 .568 corresponden a la muestra de estudio de este trabajo $(\mathrm{n}=137$ y +1.000 descargas), lo que supone el 99,98\% de las descargas mundiales. Así, las aplicaciones que quedaron fuera de la muestra se han considerado poco relevantes, independientemente de su número total.

Tabla 1. Distribución de las apps según el número de descargas.

\begin{tabular}{|l|r|r|r|r|r|}
\hline Franja de descarga & $\begin{array}{l}\text { Número } \\
\text { de apps }\end{array}$ & $\begin{array}{l}\text { Sumatorio } \\
\text { apps }\end{array}$ & $\begin{array}{l}\text { \% de la muestra } \\
\text { (sumatorio \%) }\end{array}$ & $\begin{array}{l}\text { Estimación } \\
\text { descargas }\end{array}$ & $\begin{array}{l}\text { \% } \\
\text { acumulado) }\end{array}$ \\
\hline$>50.000 .001$ & 1 & 1 & $0,73 \%(0,37 \%)$ & 50.000 .000 & $38,81 \%(38,81 \%)$ \\
\hline $5.000 .001-50.000 .000$ & 1 & 2 & $0,73 \%(0,74 \%)$ & $27.500 .000,50$ & $21,34 \%(60,15 \%)$ \\
\hline $1.000 .0001-5.000 .000$ & 5 & 7 & $3,65 \%(2,58 \%)$ & $37.500 .002,50$ & $29,10 \%(89,25 \%)$ \\
\hline $500.001-1.000 .000$ & 4 & 11 & $2,92 \%(4,06 \%)$ & 3.000 .002 & $2,33 \%(91,58 \%)$ \\
\hline $100.001-500.000$ & 18 & 29 & $13,14 \%(10,70 \%)$ & 5.400 .009 & $4,19 \%(95,77 \%)$ \\
\hline $50.0001-100.000$ & 14 & 43 & $10,22 \%(15,87 \%)$ & 4.200 .007 & $3,26 \%(99,03 \%)$ \\
\hline $10.001-50.000$ & 31 & 74 & $22,63 \%(27,31 \%)$ & $930.015,50$ & $0,72 \%(99,76 \%)$ \\
\hline $5.001-10.000$ & 21 & 95 & $15,33 \%(35,06 \%)$ & $157.510,50$ & $0,12 \%(99,88 \%)$ \\
\hline $1.001-5.000$ & 42 & 137 & $30,66 \%(50,55 \%)$ & 126.021 & $0,10 \%(99,98 \%)$ \\
\hline $501-1.000$ & 25 & 162 & $18,25 \%(59,78 \%)$ & $18.762,50$ & $0,01 \%(99,99 \%)$ \\
\hline $101-500$ & 31 & 193 & $22,63 \%(71,22 \%)$ & $9.315,50$ & $0,01 \%(100,00 \%)$ \\
\hline $0-100$ & 78 & 271 & $56,93 \%(100,00 \%)$ & 3.900 & $0,00 \%(100,00 \%)$ \\
\hline
\end{tabular}

Fuente: elaboración propia

La codificación se realizó a través de un libro de códigos que permitió a los autores y un investigador asociado la recolección de los datos que componían el análisis de contenido cuantitativo. La codificación respondió a los patrones formales que ofrecían las plataformas de distribución de contenidos complementadas por Sensor Tower aunque conviene precisar algunos aspectos de la misma. Por un lado, los desarrolladores se catalogaron según taxonomías localizadas en la literatura de referencia (Wang et al., 2017; Gómez-García et al., 2019) reconociendo 4 categorías de acuerdo con el número total de apps de cada creador: esporádicos ( 1 o 2), moderados (de 3 a 9), activos (entre 10 y 20) y, por último, los prolíficos o profesionales (más de 20 aplicaciones desarrolladas).

Además, en la recogida de datos, a la hora de codificar la variable de la categoría en la que se enmarcaba la finalidad de la app, se ha realizado la siguiente división que puede ser de utilidad en futuras investigaciones.

- Ayuda personal: El desarrollador busca hacer más llevadera la situación ofreciendo consejos y ejercicios de relajación o ideas para subir el ánimo.

- Información y atención médica: Los datos que se encuentran en la app son referentes a los efectos que genera el virus en el cuerpo y cómo es su evolución; números a los que llamar para que profesionales den contestación a las dudas médicas; o información de centros de salud más cercanos. 
- Autodiagnóstico sin envío: Explicación de los síntomas y posibilidad de que el usuario se realice una autoexploración sin posibilidad de enviar los resultados ninguna base de datos.

- Contenido para profesionales: Apps de contenido médico y asistencial para que los profesionales de una determinada área tengan las instrucciones de cómo proceder.

- Monitorización y seguimiento de personas: Aquí se hace referencia a dos posibilidades de las apps. Por un lado, la posibilidad de recopilar información del usuario (de manera anónima o no) y así poder establecer unas pautas de movimientos que realiza para tener controlado su entorno y posibles contagios. Por otro, las apps que realizan una monitorización de pacientes contagiados con el virus y poder ejecutar un seguimiento fuera del centro sanitario.

- Investigación sobre COVID-19: Herramientas con finalidad científica para poder recabar datos y comportamientos del coronavirus a través de la cooperación de usuarios.

- Datos generales sobre la pandemia: Aplicaciones desarrolladas para informar sobre la evolución de los datos de contagiados, fallecidos, enfermos que han superado la COVID-19 y países activos.

- Otros: Temática no relacionada con lo anterior. Juegos o foros para canalizarla ayuda entre vecinos, por ejemplo.

La aplicación de esta tipología se ha realizado atendiendo a la función dominante o principal de la aplicación. Así, puede ocurrir que una aplicación ofrezca un servicio destacado, y otros como complemento (por ejemplo, aplicaciones sobre estadísticas de la pandemia que proporcionan consejos sobre el lavado frecuente de manos), pero se ha considerado que son funciones secundarias. La determinación de cuál es la función dominante se ha realizado examinando el funcionamiento de la aplicación y teniendo en cuenta lo que los propios creadores destacan en la descripción de esta.

Por último, la codificación de la recepción tuvo en cuenta el rating breakdown de las plataformas de distribución, así como un análisis del tono de los comentarios para establecer el sentimiento general que trasladaban. En ese sentido, las apps se clasificaron por el tono mayoritario que podía ser positivo, negativo, divido (en caso de no apreciarse una mayor presencia de uno que de otro) o inexistente (en aquellos casos en los que no había comentarios). Para ello se ha observado el número de comentarios y su valoración según las estrellas otorgadas: cinco y cuatro estrellas correspondían a comentarios positivos; tres, neutro; y dos y una, negativo. Además, se leyeron los últimos 20 comentarios que aparecían en la plataforma para comprobar que la valoración del usuario y el comentario se correspondía a la clasificación otorgada.

Este proceso de codificación se realizó en las dos últimas semanas de mayo de 2020, Para certificar la fiabilidad de la codificación se analizó una muestra común de 54 apps que, tras dos rondas de codificación, obtuvo un 99,3\% de acuerdo en los datos obtenidos por los investigadores, Con este porcentaje, se acepta la fiabilidad, al ser apropiado "cuando se usan medidas nominales y todos los desacuerdos se consideran equivalentes" (Riffe et al., 2019: 123).

\section{Resultados y discusión}

\subsection{Evolución del ecosistema de las aplicaciones móviles sobre el coronavirus}

La primera app creada exclusivamente para la 2019-nCoV fue Coronavirus: Info\&Live Tracker (22 de enero de 2020) y fue lanzada por un desarrollador que contaba con 158 apps más en las plataformas de distribución (Programming Is Fun). En el análisis de la muestra se constató que a finales de enero ya existían 19 apps $(13,87 \%$ de la muestra) relacionadas con el tema. A partir del siguiente mes, con la extensión crecientemente rápida del virus fuera de las fronteras de China, los números se incrementaron considerablemente: en febrero aparecieron 45 aplicaciones $(32,85 \%)$; en 
marzo, con el comienzo del confinamiento en países como Italia ( 7 de marzo) o España (15 de marzo), se publicaron 61 apps (44,52\%) y en abril fueron 47 (34,30\%). Sin embargo, en mayo se produjo un marcado descenso en la aparición de nuevas aplicaciones sobre el tema, con solo 9 nuevas apps $(6,57 \%)$, posiblemente porque ya no era tan novedoso, el mercado estaba más saturado y la propia intensidad de la pandemía había remitido en los países que primero habían sufrido sus efectos. El caso de marzo es significativo, pues es donde se produjo el punto de inflexión que marcó la aceleración del ritmo de publicación y el pico de desarrollos: 46 de las 61 aplicaciones se publicaron en los 20 días que trascurrieron entre el día 11 (cuando la OMS declaró la pandemia) y el 31.

Los datos anteriores plantean la necesidad de establecer una relación entre el desarrollo de aplicaciones y la percepción de agravamiento de la pandemia, con las medidas de distanciamiento social en varios países europeos, las declaraciones de organizaciones supranacionales y el aumento de casos de fallecidos y contagiados. Esto está en línea con investigaciones precedentes, que ya habían señalado la influencia de factores externos en la producción de apps (Hilkert; Benlian; Hess, 2010; Heffernan et al., 2016; Di Ionno; Mandel, 2016). Los datos obtenidos permiten diferentes elaboraciones sobre los diferentes ritmos con los que el ecosistema móvil reaccionó a la pandemia de la COVID-19. La producción de apps durante los primeros meses del año 2020 presenta unos rasgos de interés que se reflejan en el gráfico 1.

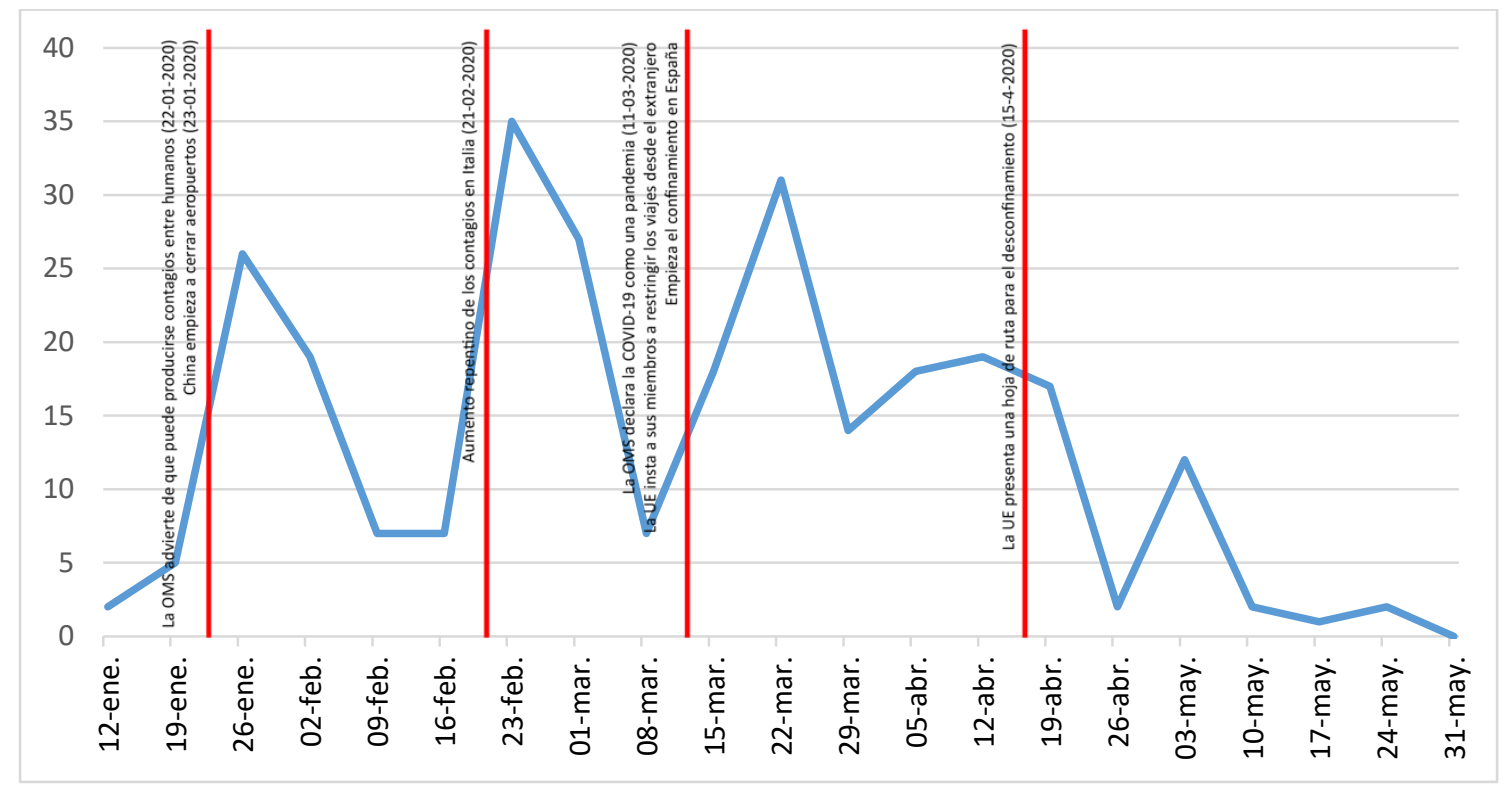

Gráfico 1. Evolución temporal de la publicación de apps sobre la Covid-19.

Fuente: elaboración propia a partir de datos propios, de la OMS (2020) y el Consejo de Europa.

En este sentido, puede comprobarse que no hay una correlación clara entre el número de fallecidos y las aplicaciones desarrolladas, sino que más bien habría que buscar la correspondencia con los signos de la evolución de la pandemia en el discurso noticioso. No obstante, hay que tener en cuenta que debe existir una diferencia temporal entre las noticias y la aparición de las apps, debido al tiempo de desarrollo. Así, los mayores incrementos porcentuales se producen a medida que el virus empieza a extenderse fuera de China y a trascender en los medios de comunicación, aunque como un acontecimiento lejano. Igualmente, puede apreciarse un segundo pico unas semanas después de que empiecen los cierres de aeropuertos en China, y otro pico, menor en este caso, unas semanas después de que empiecen a registrarse los primeros contagios en Europa. 
Un factor importante en un acontecimiento de dimensión mundial y en continua evolución, como es una crisis sanitaria, es que los datos estén actualizados para adaptarse a un escenario médico, humano y social cambiante. En ese sentido, las apps, debido a su naturaleza, pueden ser modificadas y actualizadas siempre que los desarrolladores lo estimen oportuno. No obstante, casi el $15 \%$ de ellas (20) no realizó ningún retoque. El grueso de las aplicaciones recibió actualizaciones entre la primera y octava semana desde su lanzamiento, aglutinando el 65,50\% (125) del total. De las 18 apps que tardaron menos de una semana en realizar alguna actualización, 13 llevaron a cabo algún reajuste al día siguiente de su lanzamiento.

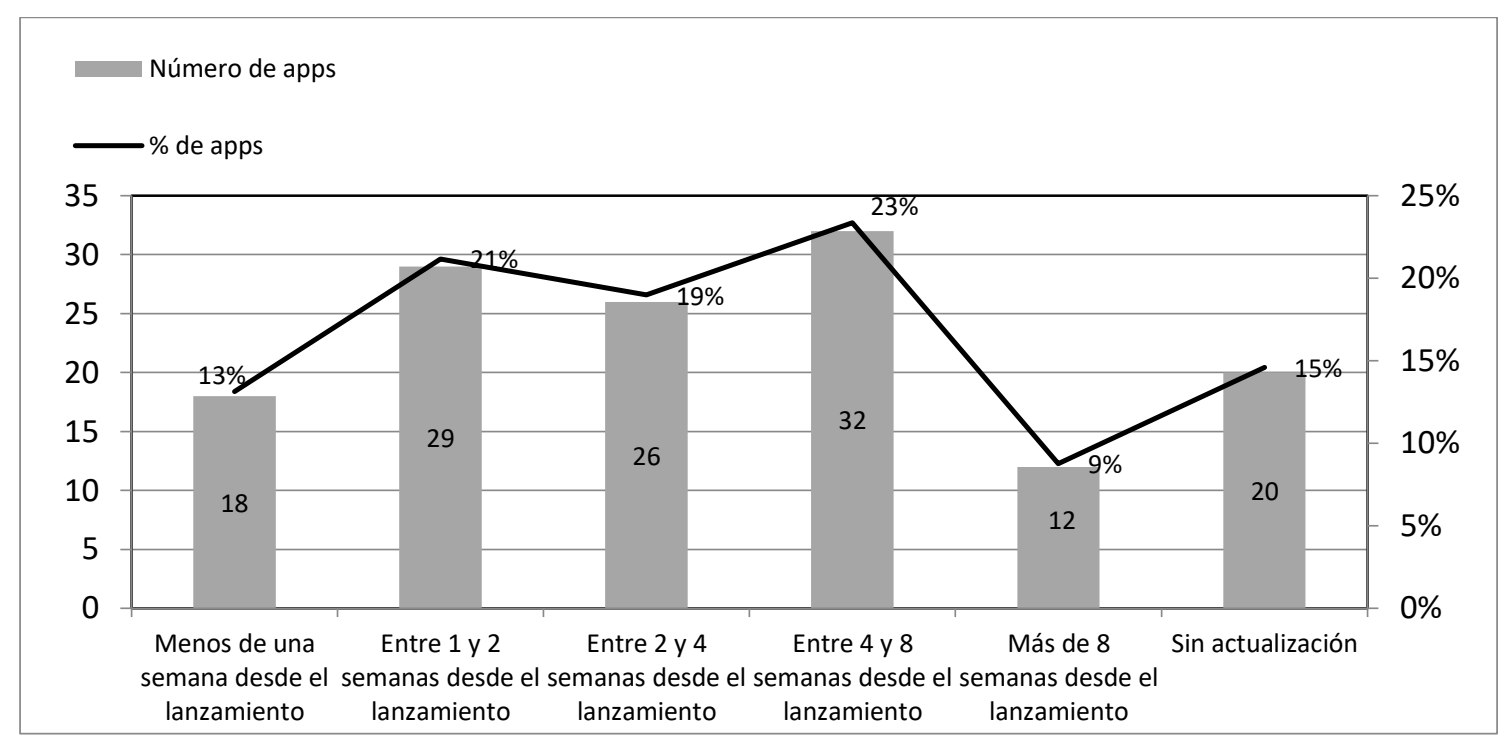

Gráfico 2. Actualizaciones de las apps más populares.

Fuente: Elaboración propia.

Los datos anteriores se relacionan con los periodos de mayor producción de apps que precedieron, como ya se ha señalado, a eventos significativos, como la declaración de emergencia sanitaria internacional, los primeros confinamientos o el reconocimiento de la enfermedad como una pandemia. En cualquier caso, este crecimiento en el lanzamiento de aplicaciones no fue, por otra parte, simultáneo ni uniforme desde el punto de vista geográfico. Si se tiene en cuenta que el ecosistema móvil abarca a todo el planeta y que se establece una relación de las aplicaciones con los países que las han desarrollado (Lim et al., 2014; Khaskheli; Jun; Bhuiyan, 2017), el mapa mundial presenta el reparto de apps desarrolladas en función de su país de procedencia: 


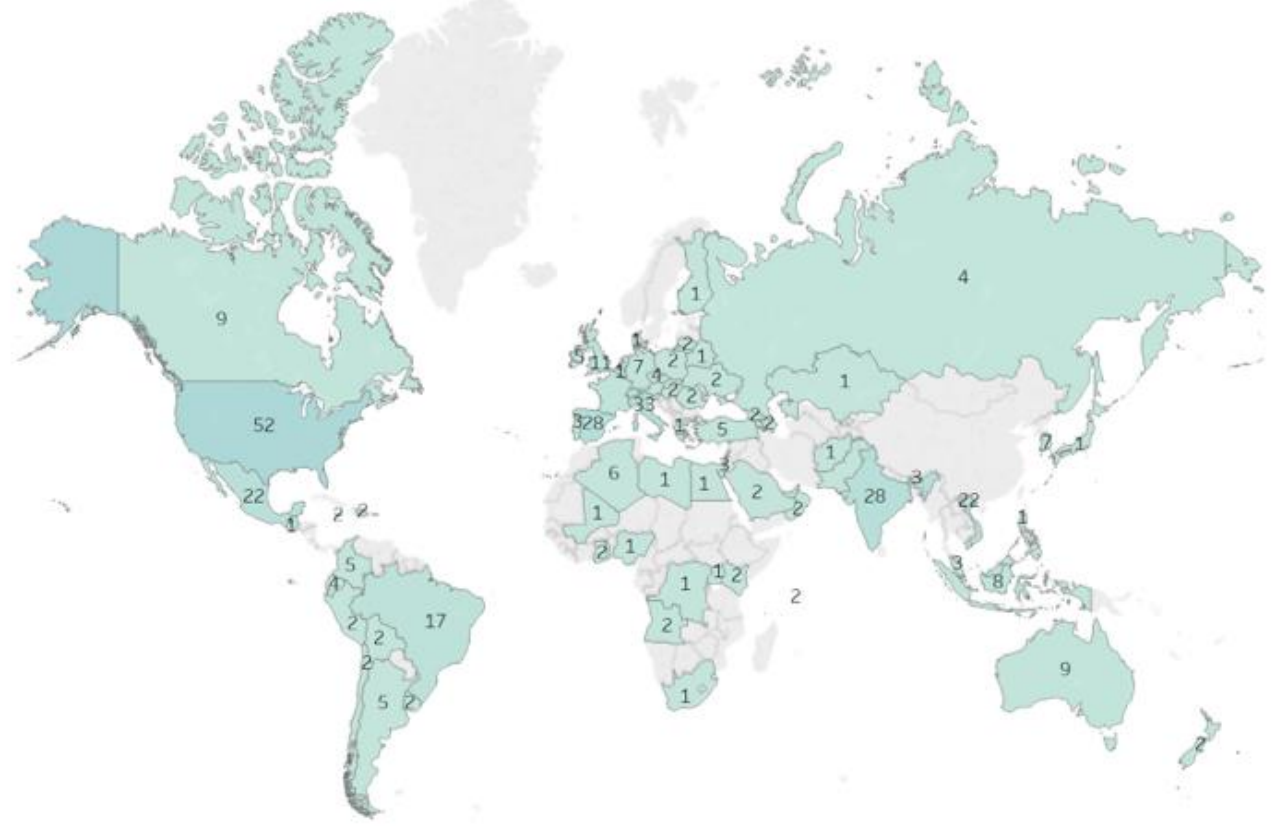

Imagen 1. Número de apps por países

Fuente: elaboración propia.

Esta imagen refleja que Estados Unidos ha sido la nación con más apps desarrolladas (52), seguida de Italia (33) y con España e India en tercer lugar (28 cada una). Estos datos contrastan con la producción de apps en años anteriores: en 2017, Estados Unidos fue también el país que más apps desarrolló, aunque con una cuota mayor del mercado $(33,5 \%)$, seguido de China $(15,9 \%)$, India $(5,1 \%)$, y Reino Unido (3,3\%) (Statista, 2017). Si bien los datos cambian de un año a otro, la variación es lo bastante significativa como para que resulte interesante cruzar los datos de la producción por países con la virulencia que ha tenido la COVID-19en ellos para concretar si este puede ser un factor relevante, al haber un estímulo mayor para desarrollar apps referidas a una crisis especialmente grave.

Según los datos de Worldometer (2020) a fecha de 12 de junio, de los 213 países y territorios afectados, cabría suponer que los países más castigados por la pandemia serían los más prolíficos en cuanto a la creación de apps sobre el coronavirus. Una circunstancia que se manifiesta en que 8 de los países más afectados (Estados Unidos, Brasil, España, Reino Unido, Italia, India, Francia y Alemania) suman ellos el 44,59\% (185 apps) del total. Por otra parte, los países que más aplicaciones han producido son, además, estados desarrollados, con un alto índice de conexiones a Internet, superior en todos los casos (excepto Canadá, México y la India) a la media mundial, y con más de una conexión móvil por persona. 


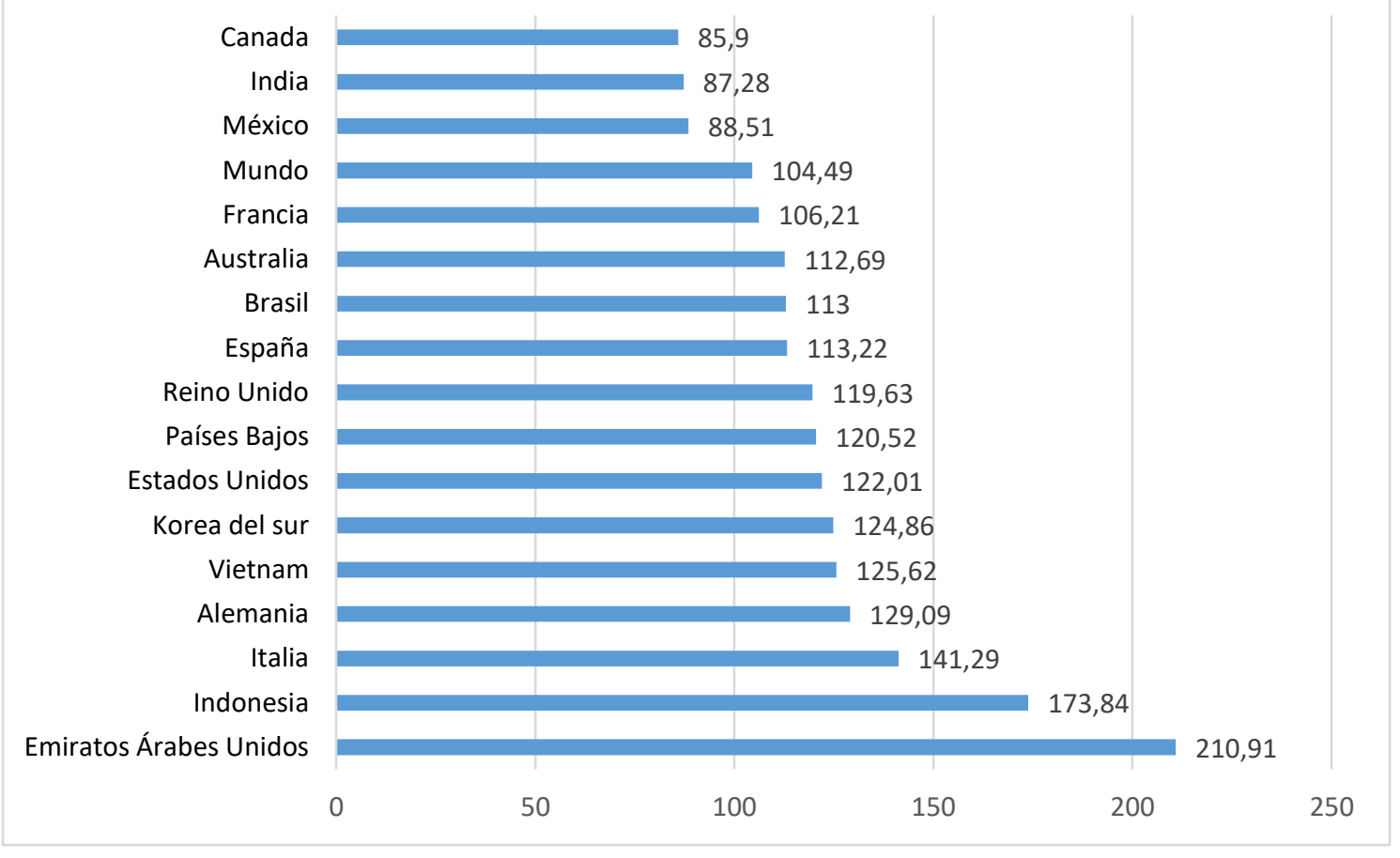

Gráfico 3. Suscripciones mensuales.

Fuente: Elaboración propia a partir de WorldinData

Sin embargo, estos números sólo reflejan una parte de la realidad, porque la abundancia de apps no implica necesariamente popularidad o una gran difusión. En ese sentido, el número de descargas (dato solo disponible en Android, porque Apple Store no ofrece esa información) es determinante. Por ello, de las 271 aplicaciones distribuidas por Google Play, es interesante destacar que las aplicaciones más descargadas fueron desarrolladas en países en vías de desarrollo. Un factor que produce este hecho es que los únicos países que desarrollaron apps que superaron los 5.000.000 de descargas fueron Colombia e India. En el primer caso, a través de Coron-App Colombia, cuyo lanzamiento estuvo reforzado por una campaña de apoyo que incluía el regalo de $1 \mathrm{gb}$ de datos y 100 minutos de llamada a todos los usuarios que reportaran sus síntomas. Un reclamo que, en el contexto del país, justificó su alta demanda, aunque como se verá más adelante, su recepción fue polémica. En el segundo caso, AarogyaSetu (que a mediados de junio de 2020 ha superado los 100 millones de descargas según Google Play) fue desarrollada por el Ministerio de Sanidad indio y su popularidad se puede situar tanto en su condición de segundo país más poblado del mundo (1.379.500.000 personas, Worldometer, 2020) como al esfuerzo de localizar la app a los diferentes idiomas del país (incluido el inglés, fomentando el consumo foráneo) o al algoritmo de Google Store, que presenta las sugerencias a nivel nacional .

El número de descargas obedece a muchos factores y no se puede precisar con los datos de que disponemos de dónde proviene el grueso de ellas. Sin embargo, si se considera que, sobre el total de descargas, se produce una proporcionalidad entre el consumo interior y exterior se podría identificar, los países en los que las apps de los dispositivos móviles generaron más interés entre los usuarios, $\mathrm{y}$, por tanto, fueron más utilizadas como herramientas para satisfacer diversas necesidades durante la crisis del coronavirus. Por ello, sobre la muestra de las aplicaciones más populares $(n=137)$, es decir, aquellas que sobrepasan las 1.000 descargas, se observa que Italia es el país con más apps descargadas (15 y un 11\%), seguido de India (13 y 9\%). España ocupa el tercer puesto con 10 aplicaciones que aglutinan entre todas el $7 \%$ de las descargas mundiales. 
RLCS, Revista Latina de Comunicación Social, 78, 329-358

[Investigación] DOI: 10.4185/RLCS-2020-1480| ISSN 1138-5820| Año 2020

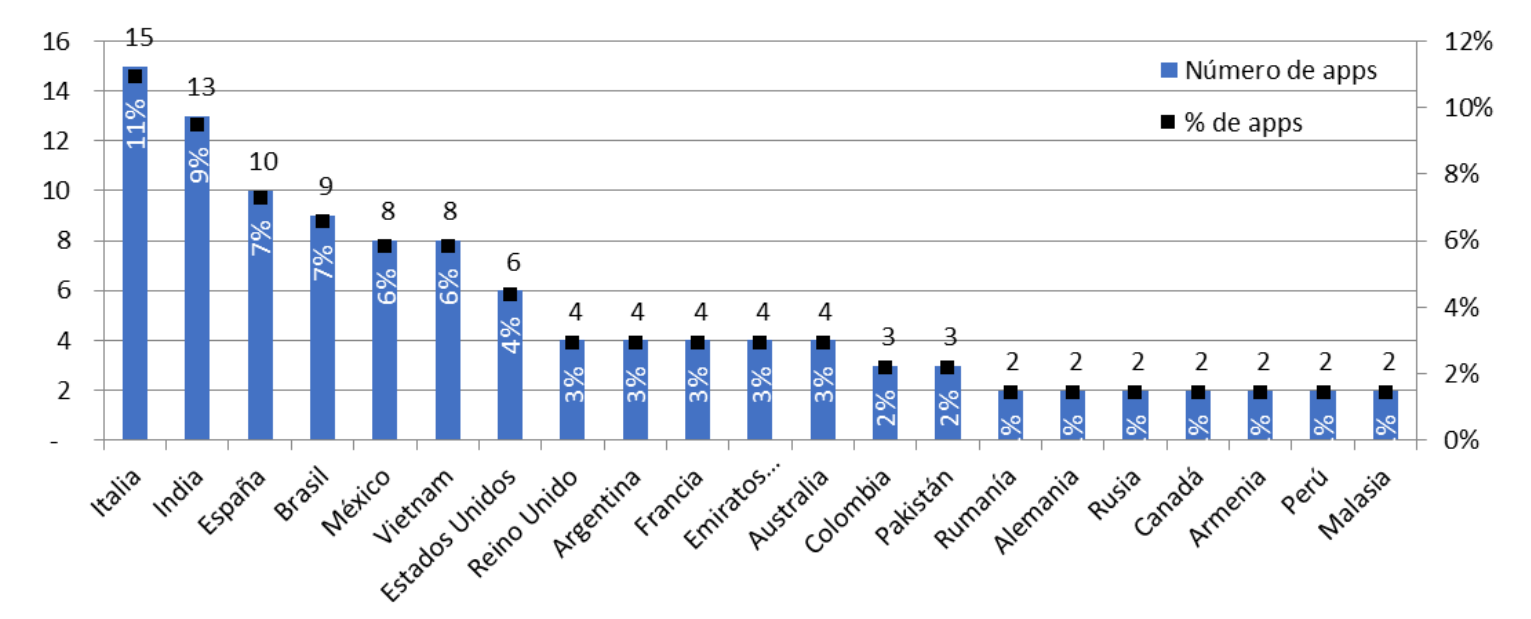

Gráfico 4: Número de apps (Android) por países

Fuente. Elaboración propia.

En este sentido, es interesante destacar que, en Italia, el país con más aplicaciones con más de 1.000 descargas cada una, la más popular fue LazioDrCovid, que además permaneció desde su aparición (19 de marzo) hasta el 9 de abril en el Top 3 de las aplicaciones gratuitas más descargadas en el país, la mayor parte del tiempo en primer lugar. Se trata de una app promovida por el gobierno y centrada, como su nombre indica, en la región de Lacio, de la cual es capital Roma, uno de los epicentros de la pandemia. La aplicación sirve para realizar un seguimiento de los signos vitales del usuario (temperatura, pulso, etc.), contactar con el centro médico más cercano o incluso que el paciente realice una consulta virtual con su médico. Por otro lado, la segunda más popular fue Coronavirus Statistics, que permitía seguir la evolución de la pandemia en el mundo a través de los datos de la Universidad Johns Hopkins. Se trata de una aplicación comercial gratuita, pero con compras integradas, a pesar de la valoración de los usuarios fue mayoritariamente positiva.

En el caso español, la aplicación más consumida fue STOP COVID19 CAT. Desarrollada por la Generalitat de Cataluña, la app tenía una doble función: por un lado, a través de un cuestionario se avisaba al usuario del riesgo que tenía de haber contraído el virus. Por otro, a través de estos datos se realizaba un seguimiento de los posibles infectados, ofreciendo mapas de calor de zonas con alta concentración de contagios.

\subsection{Características de las apps más populares}

Una emergencia como la COVID-19 que en sus primeras semanas tuvo un carácter sanitario, pero con amplias ramificaciones sociales y económicas, podía haber dado lugar a aplicaciones muy diversas. Sin embargo, de las 36 categorías de apps existentes en Google Store, las referidas a la pandemia se concentraron en sólo 12 de ellas (tabla 3) para categorizarlas. Muchos usuarios recurrieron en las primeras semanas de la pandemia a aplicaciones ya disponibles, principalmente para videoconferencias o juegos, y la presencia de apps desarrolladas específicamente para la pandemia fue minoritaria (Valverde, 2020).

La categoría Salud y fitness acaparó más de un $40 \%$ del total de las apps de la muestra, seguida de Medicina con un 27\%. Existieron también dos aplicaciones solitarias que fueron catalogadas como Productividad y Viajes y guías al que, por su contenido, podían encajar perfectamente en las dos mayoritarias. Se trata de CONFINAPP, desarrollada por la Generalitat de Cataluña para dar 
información sobre el confinamiento y el desconfinamiento (clasificada en Viajes y guías) y COVAPP, una aplicación de autodiagnóstico (en Productividad).

Tabla 2. Categorías de las apps

\begin{tabular}{|l|r|r|}
\hline Categoría & Número de apps & \% de la muestra \\
\hline Salud y fitness & 55 & $40,15 \%$ \\
\hline Medicina & 37 & $27,01 \%$ \\
\hline Noticias y revistas & 14 & $10,22 \%$ \\
\hline Herramientas & 6 & $4,38 \%$ \\
\hline Comunicación & 5 & $3,65 \%$ \\
\hline Sociedad & 5 & $3,65 \%$ \\
\hline Educación & 4 & $2,92 \%$ \\
\hline Juegos & 3 & $2,19 \%$ \\
\hline Libros y obras de consulta & 3 & $2,19 \%$ \\
\hline Mapas y navegación & 3 & $2,19 \%$ \\
\hline Productividad & 1 & $0,73 \%$ \\
\hline Viajes y guías & 1 & $0,73 \%$ \\
\hline Gran Total & 137 & $100,00 \%$ \\
\hline
\end{tabular}

Fuente: elaboración propia

Estos datos reflejan la categorización escogida por los propios desarrolladores y sus intenciones al crear estos contenidos. Resulta evidente que los esfuerzos se centraron en dos frentes concretos: salud e información. En ese sentido, destacaron las apps con información médica como AarogyaSetu (India) o Coronavírus - SUS (Brasil) o las aplicaciones de información general como CovidSafe (Australia), COVID Symptom Study (Reino Unido). En Medicina, sobresalen NCOVI, aplicación oficial del Ministerio de Salud y del Ministerio de Información y Comunicaciones vietnamita y Cuidar COVID-19 Argentina, una app del Ministerio de Salud de la República Argentina destinada a la prevención y al cuidado de la ciudadanía frente a la pandemia del Nuevo Coronavirus Covid-19, ambas en la categoría de Salud y Fitness que superan, de forma amplia, el millón de instalaciones. Sin embargo, estos datos se pueden matizar en función del rango de descargas que generaron las apps englobadas en estas categorías. 
RLCS, Revista Latina de Comunicación Social, 78, 329-358

[Investigación] DOI: 10.4185/RLCS-2020-1480| ISSN 1138-5820| Año 2020

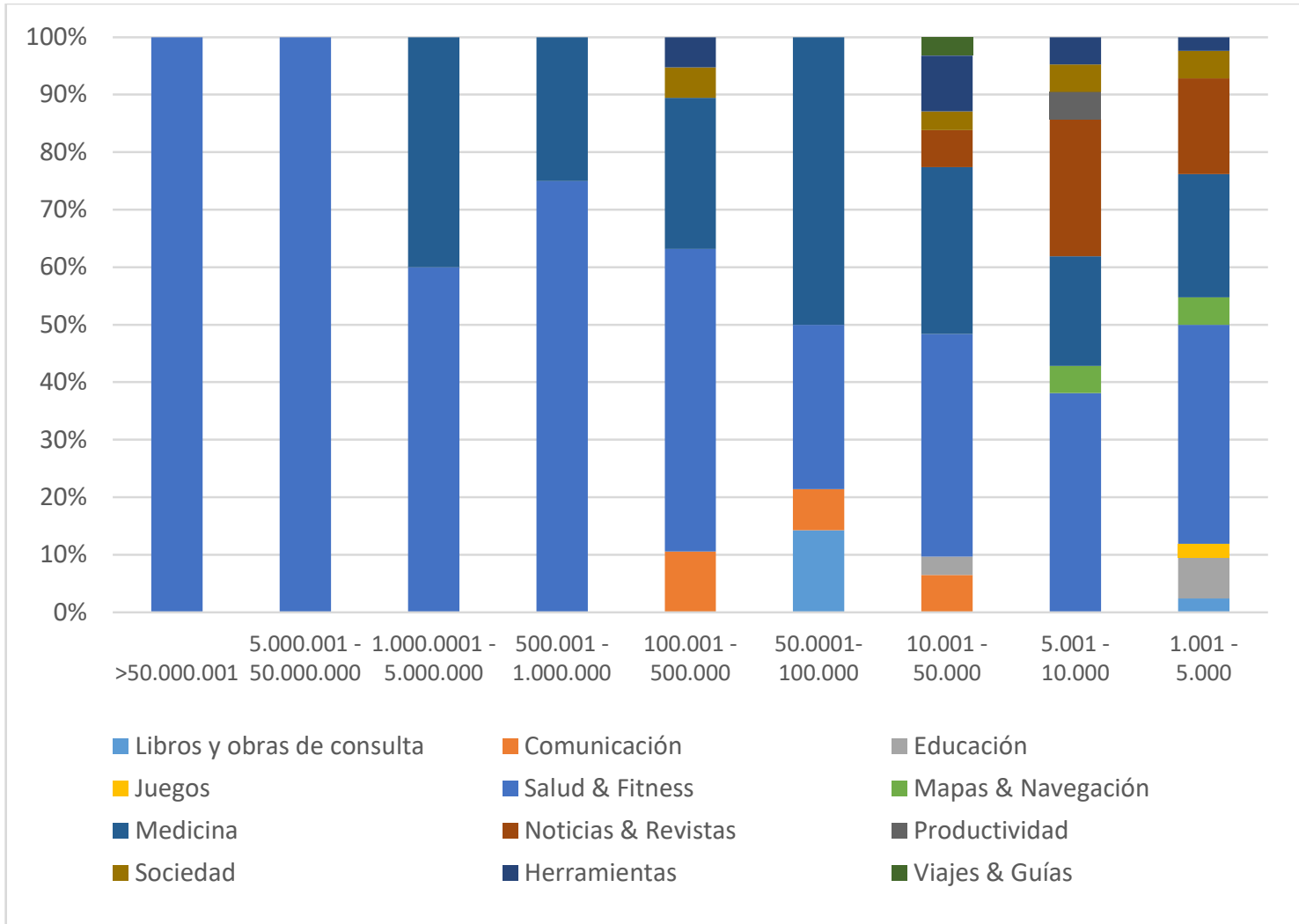

Gráfico 5. Categorías de las apps según su rango de descarga (\%)

Fuente: elaboración propia

El gráfico 5 refleja estas categorías por porcentajes según el rango de descarga. El predominio mayoritario de las categorías de Salud y Fitness y Medicina identifica que el consumo de apps respondió a los vectores principales de la epidemia en las primeras semanas, en las que la preocupación del público estaba más centrada en los aspectos inmediatos que en las consecuencias a largo plazo de la crisis. Sin embargo, cabe destacar que el 23,81\% y 16,67\% de apps englobadas en de Noticias y Revistas en las últimas horquillas de descarga, pese a que, aunque el propio sistema Android define esta categoría como "periódicos, agregadores de noticias, revistas, blogs" (Google, sf.), ninguna de las apps encontradas cumple esas características. Además, las dos apps con más de 5 millones de descargas fueron de la categoría Salud y Fitness: las ya citadas AarogyaSetu (aplicación oficial del gobierno de la India para facilitar servicios sanitarios) y CoronApp Colombia (aplicación de rastreo de la Administración colombiana).

El gráfico 6 presenta 3 utilidades mayoritarias en la creación de apps sobre la COVID-19: la información actualizada sobre la evolución de la pandemia, la monitorización y el seguimiento de la población y, por último, la información de utilidad inmediata sobre la enfermedad. El resto de las propuestas recibieron una atención mucho más minoritaria. 


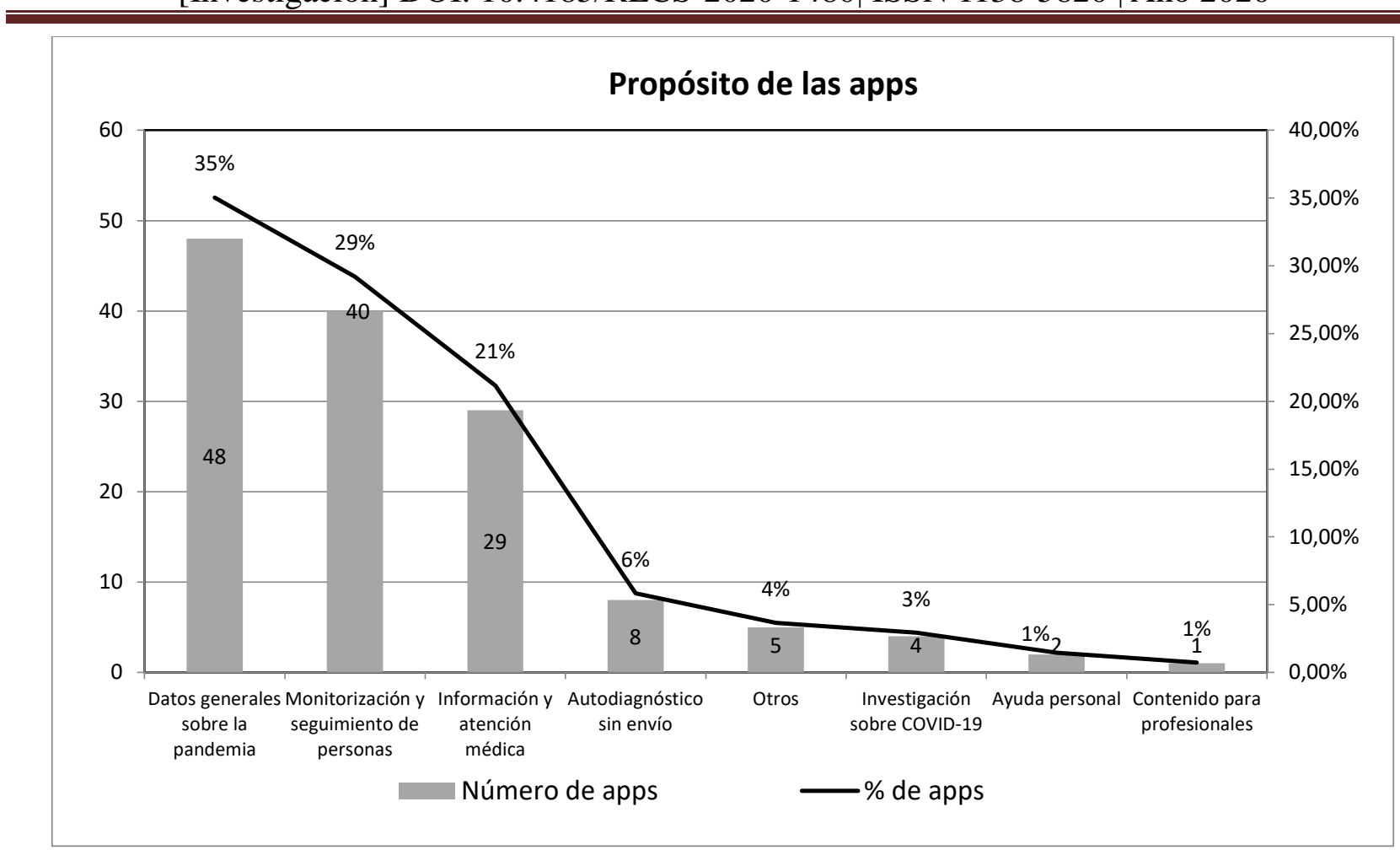

Gráfico 6. Propósito de las apps

Fuente: elaboración propia.

Se puede destacar que el porcentaje más alto se encuentra en la finalidad buscada de "Datos generales de la pandemia", con un 35\% (48). En ellas se observa cómo se facilitan datos de la evolución de la crisis: número de fallecidos, infectados, países afectados y un amplio etcétera. Por otro lado, en algunas se recogen datos básicos de higiene, datos que son interesantes para observar cómo se extiende el virus y la evolución de los contagios. Esto refleja la incertidumbre y ansiedad de los primeros momentos, presididos por falta de certezas respecto a lo que estaba pasando o el alcance que tendría. Esto encaja con el ascenso de webs como Worldometer, que se ha convertido en el proveedor de información estadística sobre la COVID-19 por excelencia para gobiernos, instituciones y la población general (Meo et al., 2020). Los contenidos son de lo más dispar, hallándose apps donde los datos aparecían fijos sin actualización alguna (Coronavirus Map) u otras que los actualizaban varias veces al día (Coronavirus - Live Monitor (nCOV-2019). La utilización de mapas para ubicar países es una constante y así lo reflejan algunas de ellas en su contenido (43) o en su nombre (6).

En segundo lugar, con un 29,2\% y 40 unidades, se localizan las apps desarrolladas para la monitorización y seguimiento de las personas enfermas. Aquí se diferencian dos grandes clases: aquellas dirigidas a la población general y las que se enfocan en monitorizar a pacientes que no están ingresados. Un ejemplo de esta última es Canada COVID-19 diseñada para saber qué acciones tomar y los pasos a seguir, ya que las recomendaciones son personalizadas y reciben alertas puntuales del Ministerio de Salud de Canadá con actualizaciones. La gestión de la información proporcionada de manera individual es un aspecto complejo que algunas apps quieren suavizar especificando abiertamente el uso que se dará a esos datos privados. La app australiana CovidSafe, por ejemplo, está muy concienciada sobre el control individual de la información vertida en ella, pero casi todas siguen la línea de la neozelandesa NZ COVID, en la que no se ofrecen garantías. 


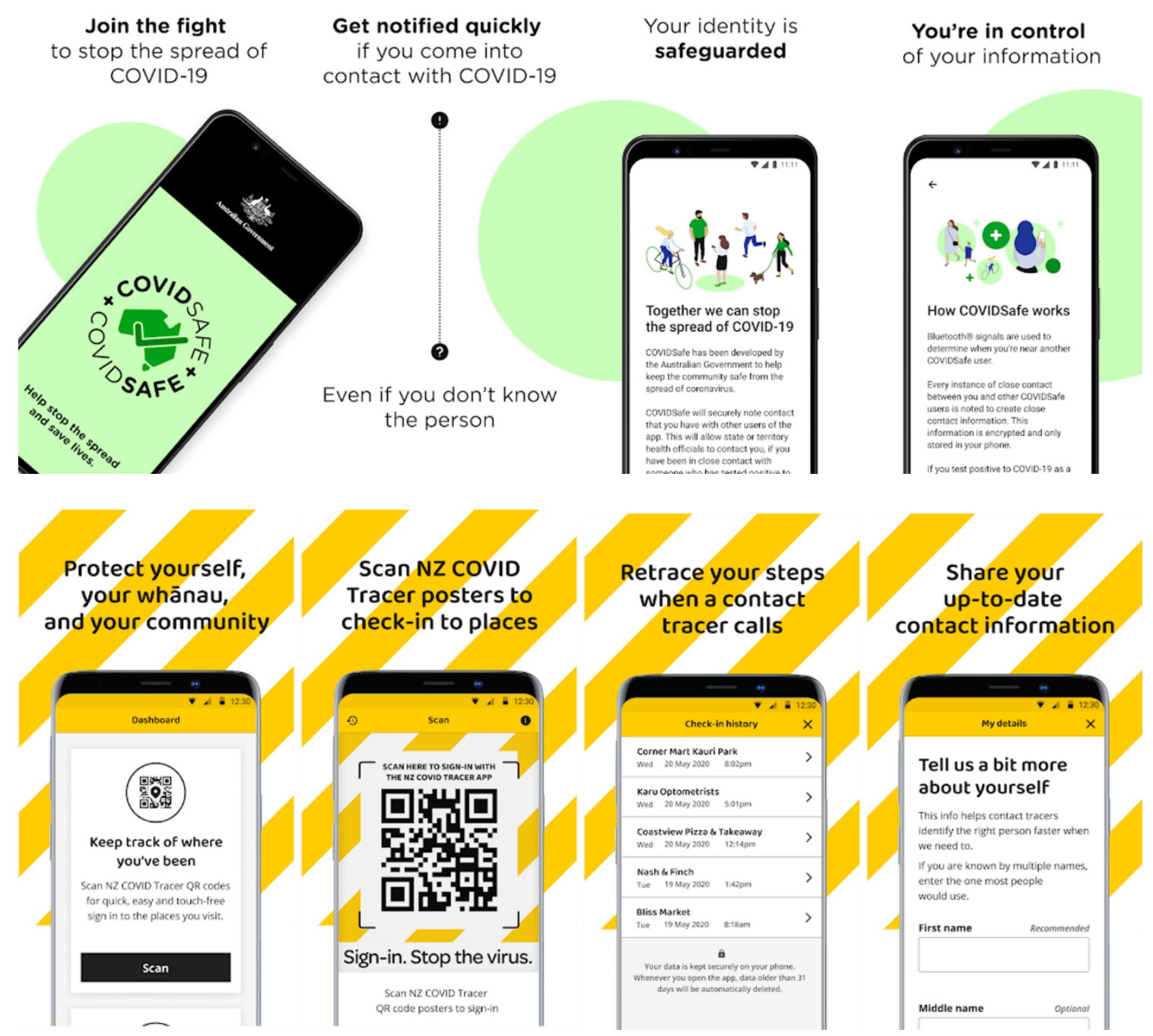

Imagen 2. Ejemplos y monitorización y seguimiento de personas: Covid Safe y NZ COVID Tracer Fuente: Recopilación de los autores a partir de Sensor Tower

A pesar de los grandes porcentajes anteriores, la información y atención médica siguen siendo relevantes, y ocupan el tercer puesto con un 21,17\% y 29 apps. En ellas se encuentran datos médicos de qué es el virus, qué síntomas produce y cómo se debe proceder para minimizar los contagios. Además, algunos brindan una autoevaluación inmediata, pero sin posibilidad de envío de datos, o señalan los centros médicos más cercanos. Como ejemplo la aplicación india Covid-19 Feedback, donde se puede proporcionar información y obtener retroalimentación sobre el tratamiento médico, aunque -conviene subrayar- esta función no responde a una interacción real o bidireccional con un organismo médico, sino que se trata de una serie de consejos que se muestran en función de la información que los usuarios introducción en las aplicaciones.

Las apps de la categoría "Autodiagnóstico sin envío" suponen un grupo caracterizado por mostrar una clasificación de indicios que pueden llevar a la sospecha de estar sufriendo la enfermedad (COVID-19 NI Symptom Checker). Aunque cuantitativamente la categoría de "Investigación sobre la COVID-19" es reducida, cualitativamente tiene relevancia: la petición de ayuda para poder realizar proyectos de investigación sobre el coronavirus. The How We Feel Project (250.000 descargas estimadas y lanzada en Estados Unidos) es una app desarrollada "fundada en marzo de 2020 por un equipo voluntario de científicos, médicos y tecnólogos de instituciones de Harvard, del MIT, el 
Instituto Médico Howard Hughes, las universidades de Pennsylvania, Stanford y Maryland o el Weizmann Institute of Science (How We Feel Project, 2020). La app pide datos personales y la presencia o no de síntomas, todo de manera anónima. Además, posee un cariz social, porque cuando se descarga por primera vez se dona una comida en colaboración con Feeding America. En el análisis se detecta que otros organismos universitarios como Universitaetsklinikum de Freiburg y Leiden University Medical Center lanzaron aplicaciones para que los usuarios que lo hubieran pasado pudieran aportar datos que ayuden a su investigación.

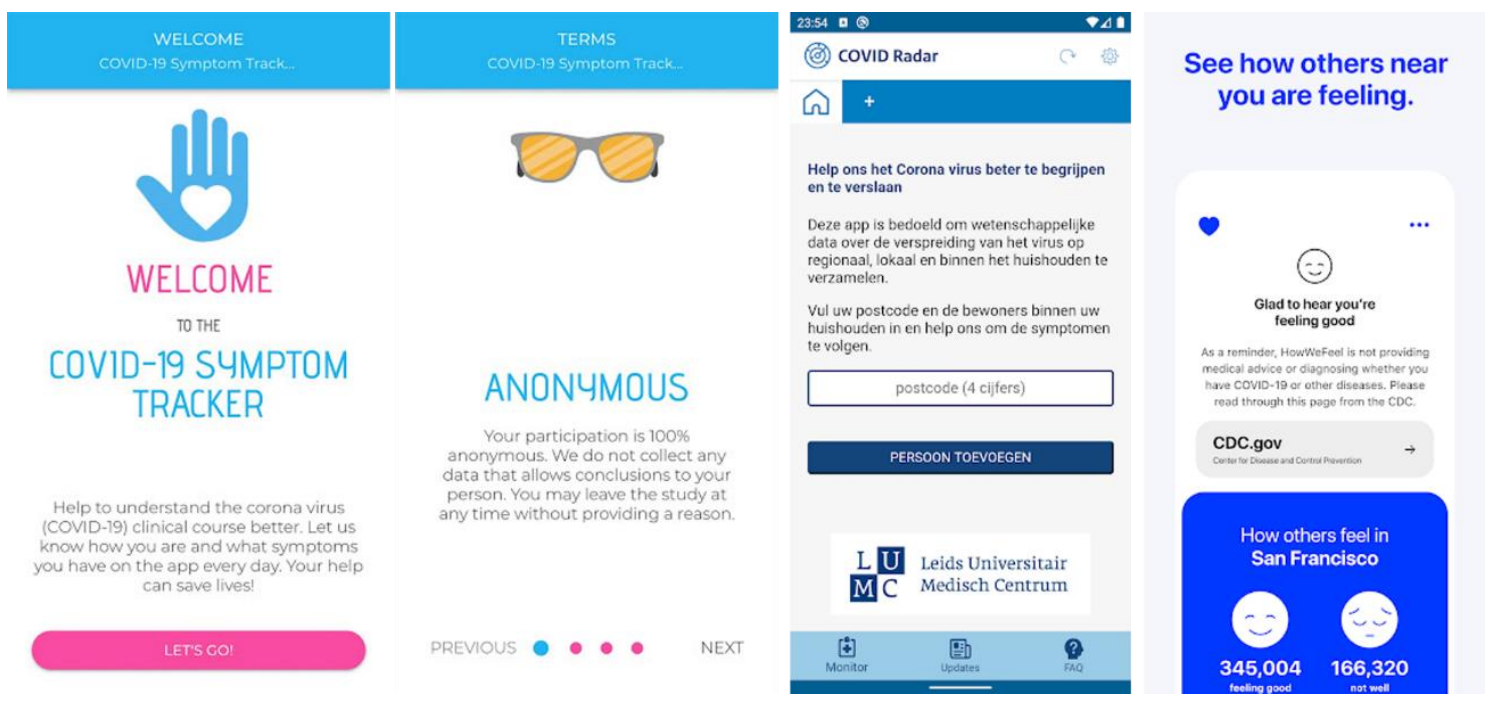

Imagen 3. Ejemplos de investigación científica: COVID-19 Symptom Tracker, COVID Radar y How We Feel.

Fuente: SensorTower.

La moral de la población fue un aspecto esencial para los gobiernos, particularmente en aquellos países obligados a un confinamiento más riguroso, como España, Francia o Italia. Por ello, no es de extrañar que aparecieran aplicaciones que ayudaran a la ciudadanía a enfrentarse a la situación generada por la COVID-19, encuadradas en la categoría "Ayuda personal". En esta línea se encuentran ConfinApp (España) y COVID Coach (Estados Unidos), apps que buscaban hacer más llevadera la situación confusa vivida. En la categoría de "Otros", se engloba el resto, como el juego Coronavirus The Game, pero también están COVIDA, de cariz humanitario, que proporcionan ayuda social o médica a los más vulnerables. También COVID-19 Provincia de Santa Fe, en la que los usuarios pueden realizar denuncias de desabastecimiento o sobreprecios en las tiendas, consultas, solicitar asistencia y mantenerse informados en relación con el asunto. Resulta llamativo que en la muestra de estudio se encontrara además una aplicación destinada al aprendizaje sobre el coronavirus (EndCorona, de Indonesia) para poder enseñar a colectivos concretos sobre cómo se comporta el virus y protegerse.

\subsection{Radiografía de los desarrolladores de las apps sobre la COVID-19}

Los rasgos que identificaban a los creadores de contenidos presentan cierto interés en un contexto que se definió por la abundancia de información, de carácter heterogéneo y, además, con una propensión a la desinformación (Cuan-Baltazar et al., 2020; Smith; Ng; Ho Cheung Li, 2020). Por ello, también se consideró de interés identificar los rasgos que definían a los desarrolladores de contenidos. A partir de la muestra de estudio $(n=137)$, se constataba que los gobiernos han sido actores activos a la hora de desarrollar apps, quedándose muy cerca de empresas o desarrolladores individuales (70). En ese sentido, la diferencia es apenas un punto porcentual ya que los gobiernos 
promovieron, de forma directa, 67 de las apps más populares (el 48,9\% del total). Sin embargo, como apunta la tabla 7, de los 11 desarrolladores que superaron las 500.000 descargas, 10 de ellos eran los propios gobiernos que, en la mayoría de los casos, estrenaban su presencia en el ecosistema móvil a través de las apps dedicadas a la COVID19.

Tabla 3. Desarrolladores y países con más descargas estimadas

\begin{tabular}{|c|c|c|}
\hline Desarrollador & País & $\begin{array}{lll}\begin{array}{l}\text { Sumatorio } \\
\text { estimadas }\end{array} & \text { de } & \text { descargas } \\
\end{array}$ \\
\hline NIC Egov Mobile Apps & India & 50.000 .000 \\
\hline Ins.Gov & Colombia & $27.500 .000,50$ \\
\hline Cục Tin Học Hóa & Vietnam & $3.000 .000,50$ \\
\hline Zoe Global & Reino Unido & $3.000 .000,50$ \\
\hline Presidencia De La Nación Argentina & Argentina & $3.000 .000,50$ \\
\hline Governo Do Brasil & Brasil & $3.000 .000,50$ \\
\hline Australian Department Of Health & Australia & $3.000 .000,50$ \\
\hline Generalitat De Catalunya & España & $750.000,50$ \\
\hline Secretaría De Salud De Mx & México & $750.000,50$ \\
\hline Digital Transformation Agency & Australia & $750.000,50$ \\
\hline National It Board & Pakistán & $750.000,50$ \\
\hline Total & & $95.500 .005,00$ \\
\hline
\end{tabular}

Fuente: elaboración propia

Estos datos reflejan que los mensajes oficiales alcanzaron una mayor difusión que sus homólogos privados. La única excepción directa a esta tendencia fue la desarrolladora Zoe Global que, en cualquier caso, está participada por el Gobierno de Gales y el Gobierno de Escocia junto al King's College de Londres. Por tanto, se puede concluir que, a pesar de las iniciativas privadas en relación con la COVID19, la confianza de un mayor número de usuarios se dirigió hacia las fuentes oficiales en aquellos países en los que los gobiernos incorporaron a las apps como parte de su estrategia informativa. En ese sentido, se advierte que los emisores son entidades gubernamentales en 3 de los rangos de los porcentajes de descargas (entre un millón y 5 millones, entre 5 millones y 50 millones y más de 50 millones). Además, los gobiernos siguen manteniendo esa primacía hasta las 100.000 descargas, donde los organismos no gubernamentales son mayoría.

Los rasgos de los desarrolladores, como se ha definido en la metodología, tuvieron en cuenta su perfil global de creación de contenidos para Google Play o Apple Store. La tabla 4 da cuenta de la popularidad de las apps con la producción de los desarrolladores para plantear si «cuantas más apps hayan creado, mayores serán las posibilidades de que sean populares» (Wang et al., 2017: 167). Esta tesis no se corresponde con el caso de estudio, ya que los datos obtenidos muestran que los desarrolladores esporádicos $(38,69 \%)$ y moderados $(34,31 \%)$ han alcanzado descargas superiores al medio millón, mientras que los activos $(15,33 \%)$ y prolíficos $(11,68 \%)$ están también presentes en los rangos inferiores. 
RLCS, Revista Latina de Comunicación Social, 78, 329-358

[Investigación] DOI: 10.4185/RLCS-2020-1480| ISSN 1138-5820| Año 2020

Tabla 4. Rango de descarga y tipo de desarrollador

\begin{tabular}{|l|l|l|l|l|l|}
\hline Rango de descarga & $\begin{array}{l}\text { Esporádico } \\
(1-2)\end{array}$ & $\begin{array}{l}\text { Moderado } \\
(3-9)\end{array}$ & $\begin{array}{l}\text { Activo } \\
(10-20)\end{array}$ & $\begin{array}{l}\text { Prolífico } \\
(>20)\end{array}$ & Total \\
\hline$>50.000 .001$ & 0 & 0 & 0 & 1 & 1 \\
\hline $5.000 .001-50.000 .000$ & 1 & 0 & 0 & 0 & 1 \\
\hline $1.000 .001-5.000 .000$ & 2 & 1 & 1 & 1 & 5 \\
\hline $500.001-1.000 .000$ & 2 & 1 & 0 & 1 & 4 \\
\hline $100.001-500.000$ & 8 & 8 & 2 & 0 & 18 \\
\hline $50.001-100.000$ & 5 & 3 & 5 & 1 & 14 \\
\hline $10.001-50.000$ & 8 & 13 & 6 & 4 & 31 \\
\hline $5.001-10.000$ & 7 & 6 & 4 & 4 & 21 \\
\hline $1.001-5.000$ & 20 & 15 & 3 & 4 & 42 \\
\hline Total & $\mathbf{5 3}$ & $\mathbf{4 7}$ & $\mathbf{2 1}$ & $\mathbf{1 6}$ & $\mathbf{1 3 7}$ \\
\hline
\end{tabular}

Fuente: elaboración propia

El cruce de las variables del propósito de las apps y la naturaleza de sus creadores refleja valores heterogéneos. Para los particulares y las entidades privadas, la categoría de datos sobre la pandemia es primordial, con un 25\% (34) del total, así como la información para profesionales es una categoría minoritaria, con solo un $1 \%$ (1). En cuanto a los gobiernos, su finalidad principal es la monitorización y seguimiento de personas con un 20\% (27) seguido de información y ayuda médica con 16 aplicaciones (12\%). Se aprecia por tanto los diferentes intereses que movieron a aquellos que percibían el uso de las apps como un servicio público o estatal frente a las iniciativas particulares, aunque no presentan datos concluyentes sobre sus motivaciones.

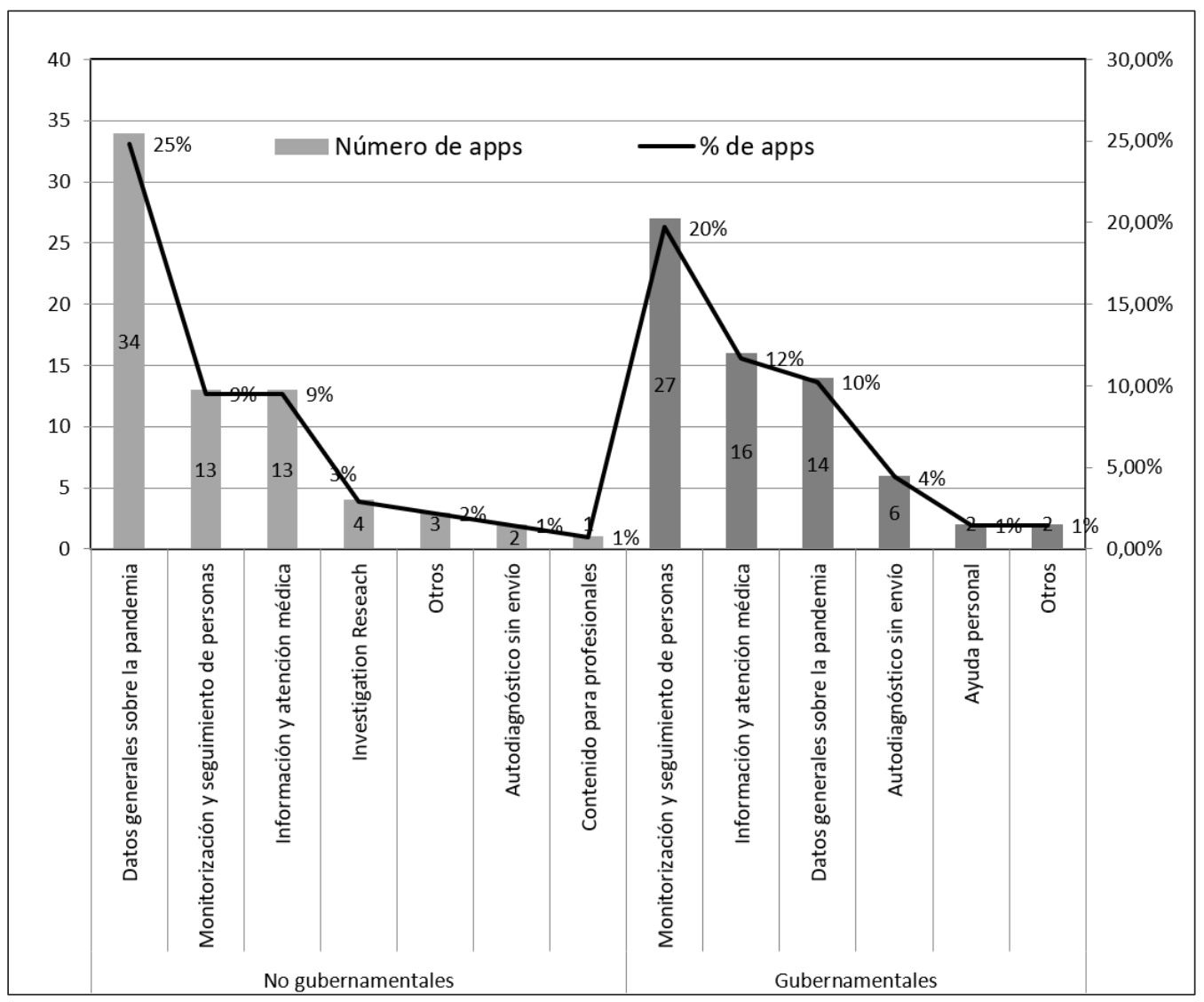

Gráfico 7. Propósito de las apps según entidades gubernamentales y no gubernamentales

Fuente: elaboración propia 
Por último, todas las apps que superaron las 1000 descargas fueron de carácter gratuito, aunque muchas de las vinculadas a iniciativas no gubernamentales respondieron a una lógica de monetización a través de la publicidad (concretamente, el 57,1\% de ellas).

\subsection{La recepción de las apps entre los usuarios}

El análisis de los datos vinculados a la recepción de las aplicaciones presenta una lógica dispar. A pesar de que la media de valoración de las apps que superaban las 1.000 descargas se situó en 3,57 puntos, el tono de los mismos presentaba una inclinación significativa hacia los comentarios positivos que se refleja en la tabla 5.

Tabla 5. Tono de los comentarios

\begin{tabular}{|l|r|r|r|r|}
\hline & Número de apps & Porcentaje de apps & Rating medio & $\begin{array}{l}\text { Media } \\
\text { comentarios }\end{array}$ \\
\hline Divididos & 17 & $12,41 \%$ & 3,325 & $1.307,53$ \\
\hline Negativos & 20 & $14,60 \%$ & 2,64 & 195,45 \\
\hline Inexistentes & 6 & $4,38 \%$ & 0,00 & 0,00 \\
\hline Positivos & 94 & $68,61 \%$ & 4,04 & $11.131,03$ \\
\hline Total & 137 & $100,00 \%$ & 3,57 & $7.828,13$ \\
\hline
\end{tabular}

Fuente: elaboración propia

Estos datos reflejan, por tanto, una lectura fundamentalmente positiva de las funcionalidades de las apps. Una consideración que se puede matizar a través del análisis cualitativo de los comentarios de los usuarios que articula una lectura de los aspectos en los que las apps llegaron a cubrir una necesidad social o, en que ocasiones, generó desagrado y por qué motivos.

A la hora de valorar de manera positiva a las apps, los usuarios se centraban principalmente en el concepto de "utilidad" que se resumía, de manera sencilla, en la "ayuda que prestaba para comprender qué hacer, cómo hacerlo o lo que el gobierno está haciendo" (BCCOVID-19 Support). Esta utilidad, aunque reconocida, no era, en muchas ocasiones, definida explícitamente por los usuarios. Cuando se hacía, se destacaba la ayuda para detectar síntomas o la posibilidad de hacerse un "chequeo rápido" (COVID-19MX) que, aunque importante en ese contexto, se solía referir a apps desarrolladas por particulares o compañías sin solvencia sanitaria. Se puede destacar que el elemento más señalado como positivo por los usuarios fue la posibilidad de acceder a la información de las apps en diferentes idiomas. De forma paradójica, más que una confianza en la información ofrecida, se hacía referencia a los idiomas en los que se ofrecía la aplicación. Los usuarios, además, destacaban su evaluación comparada de muchas aplicaciones a la hora de celebrar que "esta app es realmente útil y, además, está disponible en otros 10 idiomas, lo cual es una de sus mejores ventajas" (Corona Virus Track).

La principal crítica presente en las opiniones negativas estaba relacionada con la petición de los datos personales, aunque esta apreciación presentaba diferentes matices. Por un lado, la incertidumbre en torno a su uso posterior, aunque, curiosamente, algunos usuarios exigían algunas de estas funciones para determinar la eficacia de las apps: "Y la geolocalización no está? Pues para qué la quiero. Desinstalo" (Corona Madrid). En ocasiones, los propios usuarios cuestionaban las explicaciones de las apps sobre la solicitud de dichos datos: "Necesita activar la ubicación. ¿Por qué? Explicación: es necesario para que funcione el bluetooth??? Y por qué puedo conectar mis altavoces via bluetooth con la ubicación desactivada? Por qué puedo conectarme a mi Tablet via bluetooth cuando la 
ubicación está desactivada? Por qué puedo conectarme al manos libres del coche via bluetooth con la ubicación desactivada? Por qué puedo conectarme a mi portátil via bluetooth cuando la ubicación está desactivada? Podría continuar está lista hasta el infinito" (Coronavirus Australia).

Otros usuarios no se quejaban por proporcionar dichos datos, sino más bien porque no percibían que cederlos tuviera una utilidad definida o, incluso, porque consideraban que no se solicitaban aquellos que ellos consideraban "pertinentes" como "cefaleas, problemas digestivos, musculares, etc." (Corona Madrid). Por último, los usuarios más críticos terminaban cuestionando la app en su totalidad desde posiciones viscerales: "Una aplicación digna del gobierno. ¡Inútil!" (Coronavirus Australia).

Algunas apps concentraron esta carga crítica como, por ejemplo, NZ COVID Tracer -que poseía más del triple de comentarios negativos que positivos- porque el servicio que ofrecía -monitorización y seguimiento de personas a través de una serie de estaciones- no funcionaba. En otros casos se pueden intuir fines más espurios en la descarga de apps como Coronavirus map que no ofrecían lo que su propio nombre indicaba (un mapa): "Coronavirus map no tiene un mapa!!! Es la peor app que he visto jamás, no hay mapa, es estúpida, y ojalá pudiera darle 0 estrellas" o apps que, directamente, no funcionaban correctamente, como denunciaban los usuarios de Crush COVID RI.

Sin embargo, esta percepción no era tan unánime en todas las apps. Algunas apps recibían opiniones polarizadas como consecuencia de una experiencia desigual por parte de los usuarios. Este fue el caso de CoronApp-Colombia, una app de localización promocionada por el gobierno colombiano con un regalo para sus usuarios de 100 minutos de llamadas y $1 \mathrm{~Gb}$ de datos. Los comentarios abarcaron desde a los afortunados que podían acceder a estas ventajas sin contratiempos hasta los que, indignados, se quejaban por un supuesto engaño del gobierno o que explicaban lo necesario de su activación en diferentes contextos: "Soy maestra y muchas de las familias de mis niños han instalado esta App con la esperanza de recibir la Giga de navegación y los 100 minutos de voz, pero algunos incluso después de un mes de instalada nunca recibieron nada. Ellos son familias que no tienen Internet en sus hogares y tampoco plan de datos en sus celulares. Y desde el Ministerio de Educación se habló de esta App como una oportunidad de acceder a la educación. Espero eso sea corregido y sea una realidad" (CoronApp-Colombia).

El cruce de datos entre los comentarios de las apps y su desarrollador reflejó que los contenidos desarrollados por los gobiernos son los mejor valorados por los usuarios. De las 67 aplicaciones de origen gubernamental, 42 recibieron valoraciones mayoritariamente positivas, y, además, fueron las que generaron más interacción con los usuarios, con una media de 22.516,10 comentarios, y un rating medio de 4,03 sobre 5. Las valoraciones de las aplicaciones de desarrolladores no gubernamentales también fueron de tono mayoritariamente positivo, pero la media de comentarios fue notablemente inferior, 1.935,40, menos de la décima parte que en las apps de gobiernos. La suma de las aplicaciones de tono negativo (11) y dividido (10) y los comentarios totales de ambas $(2.422,41)$ siguen siendo inferiores a los positivos. La mejor recepción de los contenidos de los estados puede reflejar la conciencia de una mayor exposición mediática, además de unos equipos técnicos y humanos que no están al alcance de los pequeños desarrolladores.

\section{Conclusiones}

Esta investigación ofrece una primera radiografía de las tendencias de creación, distribución y consumo de las apps sobre la COVID19 que se desarrollaron durante los primeros cuatro meses del año 2020. En ese sentido, esta investigación explora cómo las aplicaciones, las manifestaciones más 
personales de un mundo hipertecnificado, han respondido y se han transformado ante una situación excepcional vivida en todo el planeta. Esto se realiza a través de las cuatro preguntas de investigación previamente planteadas.

La producción de apps tuvo una correspondencia clara con la actualidad informativa, en consonancia con investigaciones previas (Tom-Aba et al., 2018; Gómez-García et al., 2019; Planells, 2020), en las que los principales hitos informativos (la declaración de pandemia, los incrementos más significativos en los números de infectados o fallecidos, etc.) repercutieron y marcaron el ritmo de la aparición de un mayor número de apps en fechas inmediatamente posteriores. De esta forma, el desarrollo de apps respondía a los intereses del público, tanto cuando éste era creciente, en las primeras semanas, como con la ralentización en la aparición de nuevos productos cuando el peligro de la pandemia pareció hacerse menos acuciante.

No obstante, el interés por producir apps no obedeció necesariamente a la fuerza con la que la pandemia golpeó en cada país, sino a otras cuestiones. Por un lado, los factores socioeconómicos han tenido más peso en la producción de apps que la incidencia de la pandemia en cada estado. Por ejemplo, Vietnam, pese a ser uno de los países menos afectados por la COVID-19 (puesto 148), fue uno de los más activos desarrolladores, algo que podría estar relacionado con su alto índice de penetración del Internet móvil, uno de los más elevados del mundo (WorldInData, 2020). Por otro lado, también fueron relevantes los factores políticos, como la descentralización de un país: Así, por ejemplo, en España convivieron aplicaciones desarrolladas por gobiernos autonómicos, sin que, por el contrario, existiera una aplicación para todo el territorio nacional lanzada por el gobierno central. Algunos de estos gobiernos, como la Generalitat de Cataluña, lanzaron varias aplicaciones a lo largo del período del estado de alarma, lo que podría tener una lectura de búsqueda de visibilizar la labor de gobierno ante unas elecciones cercanas.

Los rasgos de discurso predominantes en las apps sobre el COVID19 fueron, de manera predecible, aquellas vinculadas con la salud y la información (77,3\%). En este sentido, y dada la variedad de dimensiones de la crisis, es llamativa la ausencia de aplicaciones en categorías como Economía o Finanzas (por ejemplo, para asesorar respecto a los requisitos de las ayudas gubernamentales), Educación (debido a la necesidad de pasar prácticamente sin aviso previo a la docencia online en todos los niveles educativos) o Juegos (para ayudar a pasar el repentino pico de tiempo libre).

Por otra parte, las aplicaciones más descargadas fueron las que proporcionaban datos estadísticos sobre la evolución de la pandemia, lo que muestra un rasgo llamativo en el consumo de los ciudadanos, que buscaban información en bruto, especialmente mapas. En este sentido, se aprecia la influencia de la actualidad en el comportamiento desarrollado por el usuario al consumir noticias en dispositivo móvil (Westlund, 2015). Otra lectura es un efecto contagio de una lógica mediática que ha ofrecido una "cobertura de ránking", centrando la información en el recuento de víctimas y en qué países tenían más muertos que otros (Masip et al., 2020).

La segunda gran categoría de aplicaciones más descargadas fueron las de seguimiento de los contagiados. La expansión de estas aplicaciones es lógica, dado que en casi todos los casos se trataba de productos desarrollados por los gobiernos, e implementados con su apoyo. En algunos países este apoyo se manifestó mediante la obligación legal de instalar la app (como en Emiratos Árabes Unidos), y en otros con incentivos y regalos, como fue el caso de Colombia, o, simplemente, mediante publicidad institucional, como ocurrió con las diversas aplicaciones desarrolladas por gobiernos autonómicos en España. En cualquier caso, este énfasis en lograr que fueran aceptadas por el público responde no sólo a motivos políticos, sino a sanitarios: su capacidad como herramienta de detección temprana y prevención de nuevos contagios depende directamente de lo extendido de su 
uso, y su efectividad aumenta exponencialmente a medida que son adoptadas por un porcentaje mayor de la población (O’Neill, 2020).

No obstante, precisamente debido a todo este apoyo y a la cobertura mediática de la pandemia, resulta llamativo que las aplicaciones informativas hayan sido más demandadas. Probablemente el motivo hay que buscarlo en la sensación de incertidumbre de las primeras semanas de la crisis.

La pandemia de COVID-19 ha supuesto la entrada repentina de muchos gobiernos en el ecosistema de las aplicaciones. La mayoría de ellos no habían publicado ninguna otra aplicación previamente, pero, sin embargo, se convirtieron en actores muy presentes, casi igualando en número a los desarrolladores privados. Más importante aún: una amplia mayoría de las aplicaciones más descargadas, 7 de 11, son gubernamentales. En parte, esta popularidad se debe a que concentraron la mayoría de sus esfuerzos en aplicaciones de seguimiento de contagiados, que, como hemos visto, recibieron un gran apoyo para ser descargadas, junto a contenidos orientados a la atención médica. El desarrollo de apps se ha configurado durante la crisis, por tanto, como un servicio público y una extensión del papel tradicional del Estado como guardián de la salud pública.

Por otra parte, los propósitos de los desarrolladores privados/particulares respondieron a intereses económicos, que reconocían los réditos de creación y distribución en la lógica de los «earned media» o en los ingresos directos que la monetización de la app promovida gracias a la demanda informativa existente en gran parte de la sociedad. En este sentido, algunas de las aplicaciones más populares fueron extremadamente sencillas, como Coronavirus Statistics, que se limitaba a reproducir estadísticas públicas, añadiendo publicidad. Igualmente, algunas mostraron un funcionamiento mejorable, o una absoluta ausencia de actividad, pese a lo cual mantuvieron una presencia destacable en los ránkings de descargas, como Coronavirus Map. En este sentido, parece que el deseo de información de la ciudadanía no fue acompañado de demasiadas exigencias.

Además, un rasgo relevante de las aplicaciones aparecidas en estas semanas, tanto públicas como privadas, es que la premura en desarrollarlas y lo cambiante de la situación no se tradujeron en un ritmo de actualización frecuente del código. Con los datos hallados, no se puede precisar si esto se debió al desinterés de los desarrolladores, a lo pulido de su diseño inicial o a la simplicidad de muchas de ellas.

Uno de los rasgos marcados de la situación mediática creada por la pandemia de COVID-19 ha sido el encuentro entre una actualidad muy cambiante y unas dinámicas cada vez más presentes en las sociedades de los últimos años, como son la sobreinformación, la desinformación y la abundancia de fake news (Pérez-Dasilva; Meso-Ayerdi; Mendiguren-Galdospín, 2020), en algunos casos, con un marcado sesgo antigubernamental. Pese a ello, las aplicaciones más descargadas (más de 95 millones de instalaciones) y mejor valoradas (tanto en la valoración media como en la participación de los usuarios, con diez veces más reseñas positivas en aplicaciones públicas que en comerciales) han sido producciones oficiales. Este carácter oficial permitía a los ciudadanos conocer de forma clara la fuente de la información que estaban recibiendo, lo cual no supone necesariamente una garantía de veracidad. En este sentido, no cabe descartar la motivación de búsqueda de seguridad en el discurso gubernamental frente a una situación incierta, aunque los datos de esta investigación no permiten verificarlo.

En definitiva, la emergencia de la COVID-19 en el ecosistema de apps para dispositivos móviles provino de la combinación de un conjunto de factores. Por una parte, las aplicaciones se constituyeron como un elemento más de la estrategia de monitorización y de información de los gobiernos para combatir la propagación del virus y la optimización de los recursos disponibles, 
aunque dejando en el aire algunas consideraciones de largo recorrido, como la privacidad de los datos o los posibles problemas de praxis médica derivados de la consulta a distancia o poco personalizada (Guseh; Brendel; Brendel, 2009; Díaz; Chaparro-Domínguez, 2018).

Finalmente, otro factor fundamental ha sido la aceptación de la popularidad de los dispositivos móviles por parte de los desarrolladores y, sobre todo, los gobiernos, que han asumido la presencia continua de estos dispositivos en la vida cotidiana, y sabido aprovechar su potencial para comunicarse directamente con los ciudadanos.

No obstante, cabe señalar una limitación principal en esta investigación: como se ha señalado previamente, la muestra solamente abarca 11 semanas y media. Sin embargo, dado lo excepcional de la situación, la rápida evolución de la crisis -la muestra abarca desde las primeras noticias del fenómeno a los inicios de los procesos de desescalada en diversos países- y la consiguiente dificultad de comparar con situaciones similares, se optó por primar la inmediatez en lugar de hacer una investigación a más largo plazo. Se pretende con esto reflejar la situación durante la primera oleada y el primer confinamiento, lo que abre la posibilidad de realizar comparaciones con la segunda oleada y los sucesivos confinamientos, si los hubiere.

\section{Referencias}

Anghel, B., Cozzolino, M., y Lacuesta, A. (2020). El teletrabajo en España. Boletín Económico, (2/2020), pp.1-20.

App Annie Intelligence (2020). Weekly Time Spent in Apps Grows 20\% Year Over Year as People Hunker Down at Home. https://www.appannie.com/en/insights/market-data/weekly-time-spent-inapps-grows-20-year-over-year-as-people-hunker-down-at-home/

Badía Valdés, A.T. (2013). La radio. Un salto de la web al móvil, que pasa por las redes sociales. Chasqui (Quito), (13), 27-33 https://doi.org/10.16921/chasqui.v0i123

Baltar, F. y Brunet, I. (2012). Social research 2.0: Virtual snowball sampling method using Facebook. Internet Research, 22 (1), 57-74. http://dx.doi.org/10.1108/10662241211199960

Berlanga-Fernández, I., Gozalvez-Pérez, V., Renés Arellano, P. y Aguaded-Gómez, I. (2018). Diez años de Smartphones. Un análisis semiótico-comunicacional del impacto social de la telefonía móvil. Aula Abierta, 47(3), 299-306. https://doi.org/10.17811/rifie.47.3.2018.299-306

Betarte, G.; Campo, J. D.; Delgado, A.; Ezzatti, P.; Forteza, Á.; González, L.; Martín, Á.; Muracciole, B. \& Ruggia, R. (2020). Desafíos de seguridad y privacidad en el diseño e implementación de soluciones de rastreo de proximidad. PEDECIBA. http://www.pedeciba.edu.uy/docspd/covid_CT_position_betarteetal-1.pdf

Boberg, S., Quandt, T., Schatto-Eckrodt, T. y Frischlich, L. (2020). Pandemic populism: Facebook pages of alternative news media and the corona crisis--A computational content analysis. https://arxiv.org/abs/2004.02566

Cano-Orón, L., Vengut-Climent, E., y Moreno-Castro, C. (2020). Mental health images on the Internet: A Facebook and digital media content analysis in Spanish. Revista Prisma Social, (29), 240-259. https://revistaprismasocial.es/article/view/3338 
Chen, S., Yang, J., Yang, W., Wang, C. y Bärnighausen, T. (2020). COVID-19 control in China during mass population movements at New Year. The Lancet, 395, (10226), 764-766. https://doi.org/10.1016/S0140-6736(20)30421-9

Cho, H., Ippolito, D. y Yu, Y. W. (2020). Contact tracing mobile apps for COVID-19: Privacy considerations and related trade-offs. https://arxiv.org/abs/2003.11511

Consejo de Europa (2020): Cronología: actuaciones del Consejo en relación con la COVID-19. https://www.consilium.europa.eu/es/policies/coronavirus/timeline/

Costa-Sánchez, C. (2014). Las singularidades del medio móvil: integración multimedia, personalización, geolocalización y participación. Estudio de su presencia en las apps de la prensa española. Palabra Clave, 17(3), 672-694. http://dx.doi.org/10.5294/pacla.2014.17.3.5

Costa-Sánchez, C. y López-García, X. (2020). Comunicación y crisis del coronavirus en España. Primeras lecciones. El profesional de la información, 29 (3), e290304. https://doi.org/10.3145/epi.2020.may.04

Cuan-Baltazar J. Y.; Muñoz-Pérez M. J.; Robledo-Vega C; Pérez-Zepeda M. F y Soto-Vega, E. (2020). Misinformation of COVID-19 on the Internet: Infodemiology Study. JMIR Public Health Surveill, 6, (2), e18444. https://doi.org/10.2196/18444

Cuesta, U., Cuesta, V., Martínez, L. \& Niño, J. I. (2020). Smartphone: en comunicación, algo más que una adicción. Revista Latina de Comunicación Social, 75, 367-381. https://doi.org/10.4185/RLCS-2020-1431

Di Ionno, M.\& Mandel, M. (2016): Tracking Colombia’s App Economy. Progress. Policy Inst, 1. https://www.progressivepolicy.org/wp-content/uploads/2016/10/Colombia-ENGLISH.pdf.

Díaz del Campo Lozano, J. \& Chaparro-Domínguez, M. (2018). Los desafíos éticos del periodismo en la era del big data: análisis de códigos deontológicos latinoamericanos. Palabra Clave, 21(4), 1136-1163. https://doi.org/10.5294/pacla.2018.21.4.8

Fu, Y. C., \& Lee, H. W. (2020). Daily Contacts Under Quarantine amid Limited Spread of COVID19 in Taiwan. International Journal of Sociology, 1-11. https://doi.org/10.1080/00207659.2020.1786636.

Gómez García, S. \& Cabeza San Deogracias, J. (2016). El discurso informativo de los newsgames: el caso Bárcenas en los juegos para dispositivos móviles. Cuadernos.Info, 38, 137-148. https://doi.org/10.7764/cdi.38.593

Gómez-García, S.; Gil-Torres, A.; Carrillo-Vera, J. A.\& Navarro-Sierra, N. (2019). Creando a Donald Trump: Las apps en el discurso político sobre el presidente de Estados Unidos. Comunicar: Revista científica iberoamericana de comunicación y educación, 59, 49-59. https://doi.org/10.3916/C59-2019-05

Google (sf.). Categorías y etiquetas para aplicaciones y juegos. Google Support. https://support.google.com/googleplay/android-developer/answer/113475?hl=es 
Guseh, J. S., Brendel, R. W. \& Brendel, D. H. (2009). Medical professionalism in the age of online social networking. Journal of medical ethics, 35(9), 584-586. https://doi.org/10.1136/jme.2009.029231

Gvili, Y. (2020). Security Analysis <of the Covid-19 Contact Tracing Specifications by Apple Inc. and Google Inc. Cryptomnium LLC, Tech. Rep., 2020. https://eprint.iacr.org/2020/428

Heffernan, K. J., Chang, S.; Maclean, S. T., Callegari, E. T., Garland, S. M., Reavley, N. J., Varigos, G. A. \& Wark, J. D. (2016). Guidelines and recommendations for developing interactive eHealth apps for complex messaging in health promotion. JMIR mHealth and uHealth, 4(1), e14. https://doi.org/10.2196/mhealth.4423

Hilkert, D., Benlian, A. \& Hess, T. (2010). Motivational Drivers to Develop Apps for Social Software-Platforms: The Example of Facebook. AMCIS 2010 Proceedings. Paper 86. http://aisel.aisnet.org/amcis2010/86

Human Rights Watch (2020). Mobile Location Data and Covid-19: Q\&A. HRW. https://www.hrw.org/news/2020/05/13/mobile-location-data-and-covid-19-qa

Igartua, J.-J., Ortega-Mohedano, F. \& Arcila-Calderón, C. (2020). Communication use in the times of the coronavirus. A cross-cultural study. El profesional de la información, 29 (3), e290318. https://doi.org/10.3145/epi.2020.may.18

Khaskheli, A., Jun, Y. \& Bhuiyan, M.A. (2017). M-commerce and mobile apps: opportunities for SMEs in developing countries. Journal of Internationa Bussines Reseand and Marketing, 2, (2), 20-23. https://doi.org/10.18775/jibrm.1849-8558.2015.22.3003

Kim, M. S. (2020). South Korea is watching quarantined citizens with a smartphone app. MIT Technology Review. https://www.technologyreview.com/author/max-s-kim/.

Kishore, N.; Kiang, M.; Engø-Monsen, K.; Vembar, N.; Balsari, S. \& Buckee, C. (2020). Mobile phone data analysis guidelines: applications to monitoring physical distancing and modeling COVID-19. OSF Preprints. http://doi.org/10.31219/osf.io/5arjy.

Kitchin, R. (2020). Using digital technologies to tackle the spread of the coronavirus: Panacea or folly. The Programmable City Working Paper 44.: http://progcity.maynoothuniversity.ie/wpcontent/uploads/2020/04/Digital-tech-spread-ofcoronavirus-Rob-Kitchin-PC-WP44.pdf

La Moncloa (2020). La aplicación oficial de autodiagnóstico AsistenciaCOVID-19, disponible ya en cinco nuevas comunidades autónomas. https://www.lamoncloa.gob.es/serviciosdeprensa/notasprensa/asuntoseconomicos/Paginas/2020/060420-asistencia-covid19.aspx.

Lázaro-Rodríguez, P. y Herrera-Viedma, E. (2020). Noticias sobre Covid-19 y 2019-nCoV en medios de comunicación de España: el papel de los medios digitales en tiempos de confinamiento. El profesional de la información, 29 (3), e290302. https://doi.org/10.3145/epi.2020.may.02 
Light, B.; Burgess, J. y Duguay, S. (2016). The walkthrough method: An approach to the study of apps. New Media \& Society, 20 (3) 881-900. https://doi.org/10.1177/1461444816675438

Lim, S. L.; Bentley, P. J.; Kanakam, N.; Ishikawa, F. y Honiden, S. (2014): Investigating country differences in mobile app user behavior and challenges for software engineering. IEEE Transactions on Software Engineering, 41(1), 40-64. https://doi.org/10.1109/TSE.2014.2360674

Masip, P.; Aran-Ramspott, S.; Ruiz-Caballero, C.; Suau, J.; Almenar, E. y Puertas-Graell, D. (2020). Consumo informativo y cobertura mediática durante el confinamiento por el Covid-19: sobreinformación, sesgo ideológico y sensacionalismo. El profesional de la información, 29 (3), e290312. https://doi.org/10.3145/epi.2020.may.1

Meo, S. A.; Al-Khlaiwi, T.; Usmani, A. M.; Meo, A. S.; Klonoff, D. C. y Hoang, T. D. (2020). Biological and epidemiological trends in the prevalence and mortality due to outbreaks of novel coronavirus COVID-19. Journal of King Saud University-Science, 32(4), 2495-2499. https://doi.org/10.1016/j.jksus.2020.04.004

Montero-Díaz, J.; Cobo, M.; Gutiérrez-Salcedo, M.; Segado-Boj, F. \& Herrera-Viedma, E. (2018). A science mapping analysis of 'Communication' WoS subject category (1980-2013). Comunicar, 55, 81-91. https://doi.org/10.3916/C55-2018-08

Muñoz, R. (2018). El número de líneas móviles supera por primera vez a la población mundial. El País, 27 de febrero. https://elpais.com/tecnologia/2018/02/27/actualidad/1519725291_071783.html

Navarro-Sierra, N. \& Quevedo-Redondo, R. (2020). El liderazgo político de la Unión Europea a través del ecosistema de aplicaciones móviles. Revista Prisma Social, (30), 1-21. https://revistaprismasocial.es/article/view/3731

Newzoo (2019). Newzoo Global Mobile Market Report 2019. Light Version. https://newzoo.com/insights/trend-reports/newzoo-global-mobile-market-report-2019-lightversion/

O'Neill, P. H. (2020). No, coronavirus apps don't need $60 \%$ adoption to be effective. MIT Technology Review. https://www.technologyreview.com/2020/06/05/1002775/covid-appseffective-at-less-than-60-percent-download/

Organización Mundial de la Salud (2020). Alocución de apertura del Director General de la OMS en la rueda de prensa sobre la COVID-19 celebrada el 11 de marzo de 2020. OMS. https://www.who.int/es/dg/speeches/detail/who-director-general-s-opening-remarks-at-the-mediabriefing-on-covid-19---11-march-2020.

Pan, X.-B. (2020). Application of personal-oriented digital technology in preventing transmission of COVID-19, China. Irish Journal of Medical Science, 1-2. https://doi.org/10.1007/s11845-020$\underline{02215-5}$

Pérez-Dasilva, J.-Á.; Meso-Ayerdi, K. y Mendiguren-Galdospín, T. (2020): Fake news y coronavirus: detección de los principales actores y tendencias a través del análisis de las conversaciones en Twitter. El profesional de la información, 29(3), e290308. 
https://doi.org/10.3145/epi.2020.may.08

Planells de la Maza, A. (2020). Los videojuegos como mundos ludoficcionales críticos: el caso de la crisis política española en el ocio digital móvil (2008-2015). Comunicación y Sociedad, 1-16. https://doi.org/10.32870/cys.v2020.7365

Riffe, D.; Lacy, S. y Fico, F. (2014). Analyzing media messages. Using quantitative content analysis in research. New York: Routledge. https://doi.org/10.4324/9780203551691

Rodero, E. (2020). Radio: the medium that best copes in crises. Listening habits, consumption, and perception of radio listeners during the lockdown by the Covid-19. El profesional de la información, v. 29(3), e290306. https://doi.org/10.3145/epi.2020.may.06

Scolari, C.A., Navarro Güere, H., Pardo Kuklinski, H., García, I. y Soriano. J. (2009). Comunicación móvil: actores y producción de contenidos en Cataluña Mobile. Comm \& Soc., 22(2), 159-186.

Smith, G. D.; Ng, Fowie y Ho Cheung Li, W. (2020). COVID-19: Emerging compassion, courage and resilience in the face of misinformation and adversity. Journal of clinical nursing, 29(9-10), 1425-1428. https://doi.org/10.1111/jocn.15231

Statista (2017). "Leading countries based on mobile app releases in 2017". https://www.statista.com/statistics/934739/countries-most-app-releases/

Statista (2019). En 2019 el consumo de internet superó al de la televisión. Satista. https://es.statista.com/grafico/14411/el-consumo-de-internet-sobrepasa-al-de-la-tv/

Tom-Aba, D., Nguku, P. M.; Arinze, C. Ch. y Krause, G. (2018). Assessing the Concepts and Designs of 58 Mobile Apps for the Management of the 2014-2015 West Africa Ebola Outbreak: Systematic Review. JMIR Public Health Surveill, 4(4), e68. https://doi.org/10.2196/publichealth.9015

Valverde, B. (2020). Menos Tinder y más Zoom, el confinamiento según las 'apps' más populares, en El País $\quad$ Verne, 2 de mayo. https://verne.elpais.com/verne/2020/05/01/articulo/1588330590_985171.html.

Wang, H., Liu, Z., Guo, Y., Xiangqun, C., Miao, Z., Guoai, X., y Jason, H. (2017). An Explorative Study of the Mobile App Ecosystem from App Developers' Perspective. International World Wide Web Conference Committee, 163-172. https://doi.org/10.1145/3038912.3052712

Westlund, O. (2015). News consumption in an age of mobile media: Patterns, people, place, and participation. Mobile Media \& Communication, 3(2), 151-1. https://doi.org/10.1177/2050157914563369

WHO (2020). Novel coronavirus (2019-nCoV): situation report-1. World Health Organization. https://apps.who.int/iris/handle/10665/330760

Worldometer (2020). Reported Cases and Deaths by Country, Territory, or Conveyance. https://www.worldometers.info/coronavirus/ 
World in Data (2020): Internet. En https://ourworldindata.org/internet\#all-charts-preview

Ye Q.; Zhou J. y Wu H. (2020). Using Information Technology to Manage the COVID-19 Pandemic: Development of a Technical Framework Based on Practical Experience in China. JMIR Med Inform 8(6), e19515. https://doi.org/10.2196/19515

Zamora-Medina, R.; Losada-Díaz, J.-C. y Vázquez-Sande, P. (2020). A taxonomy design for mobile applications in the Spanish political communication context. El Profesional de la información, 29(3), e290327. https://doi.org/10.3145/epi.2020.may.27

\title{
AUTOR/ES:
}

\author{
Alicia Gil-Torres \\ Doctora en Periodismo (Premio Extraordinario), Máster en Consultoría Política, Licenciada en \\ Publicidad y Relaciones Públicas y Graduada en Periodismo. Profesora Ayudante Doctor en la \\ Universidad de Valladolid en el grado de Periodismo. Miembro del proyecto de investigación \\ «Politainment en el entorno de la posverdad: nuevas narrativas, clickbait y gamificación» y del GIR \\ Nuteco. Sus líneas de investigación son comunicación política, campañas electorales y \\ comunicación. \\ alicia.gil@uva.es \\ Índice H: 3 \\ Orcid ID: http://orcid.org/0000-0002-8042-2208 \\ Google Scholar: https://scholar.google.es/citations?user=sYmJrS4AAAAJ\&hl=es \\ ResearchGate: https://www.researchgate.net/profile/Alicia_Gil-Torres \\ Scopus ID: https://www.scopus.com/authid/detail.uri?authorId=57195761187 \\ Academia.edu: https://uva-es.academia.edu/AGilTorres
}

\section{Juan Martín-Quevedo}

Profesor ayudante doctor de Proyectos en la red en los grados de Periodismo y Comunicación audiovisual de la Universidad Rey Juan Carlos. Miembro del grupo de investigación Comunicación y Sociedad Digital en la Universidad Internacional de La Rioja. Sus líneas de investigación son redes sociales, comunicación científica e historia de los medios.

Juan.martin.quevedo@urjc.es

Índice H: 7

Orcid ID: http://orcid.org/0000-0003-1005-0469

Google Scholar: https://scholar.google.es/citations?user=BmywGm8AAAAJ\&hl=es

Scopus ID: $\underline{\text { https://www.scopus.com/authid/detail.uri?authorId=56045554400 }}$

\section{Salvador Gómez-García}

Doctor, con mención internacional, por la Universidad Complutense de Madrid, Profesor Titular y Coordinador del Área de Periodismo de la Universidad de Valladolid. Ha sido profesor visitante en la Universidad Erasmo de Róterdam, Universidad Católica de Santiago de Chile e I.T. de Copenhague entre otras instituciones. Su línea de investigación actual se inscribe en la narrativa de los nuevos medios de comunicación. Ha publicado más de una veintena de artículos en revistas científicas indexadas, como en Comunicar, Intefaçe: Comunicação, Saúde, Educação, Revista Latina de Comunicación Social, Estudios del Mensaje Periodístico, Cuadernos.info o Palabra Clave.

salvadorgomez@hmca.uva.es

Índice H: 12

Orcid ID: https://orcid.org/0000-0001-5126-6464

Google Scholar: https://scholar.google.es/citations?user=O6F3WoYAAAAJ\&hl=en

ResearchGate: https://www.researchgate.net/profile/Salvador_Gomez2 
Scopus ID: https://www.scopus.com/authid/detail.uri?authorId=55329857100

Academia.edu: https://uva-es.academia.edu/SalvadorG\%C3\%B3mezGarc\%C3\%ADa

\section{Cristina San José-De la Rosa}

Doctora en Periodismo, Máster en Profesorado de Educación Secundaria Obligatoria y Bachillerato, Formación Profesional y Enseñanzas de Idiomas, Licenciada en Periodismo y Licenciada en Filología Hispánica. Profesora en la Universidad de Valladolid en el grado de Periodismo. Sus líneas de investigación son periodismo y cine y medios de comunicación.

cristina.sanjose@uva.es

Índice $\mathrm{H}: 2$

Orcid ID: http://orcid.org/0000-0001-6891-3170

Google Scholar: http://orcid.org/0000-0001-6891-3170

ResearchGate: https://www.researchgate.net/profile/Cristina_San_Jose_De_La_Rosa

Academia.edu: http://uva-es.academia.edu/CristinaSanJos\%C3\%A9delaRosa 